UNIVERSIDADE DE SÃO PAULO

ESCOLA DE EDUCAÇÃO FÍSICA E ESPORTE

EFEITOS DE UM PROGRAMA DE ATIVIDADES MOTORAS NAS VARIÁVEIS DA FUNÇÃO PULMONAR DE IDOSOS

Lucília Kunioshi Utiyama

SÃo PAULO 


\title{
EFEITOS DE UM PROGRAMA DE ATIVIDADES MOTORAS NAS VARIÁVEIS DA FUNÇÃO PULMONAR DE IDOSOS
}

\author{
LUCÍLIA KUNIOSHI UTIYAMA
}

Dissertação apresentada à Escola de Educação Física e Esporte da Universidade de São Paulo, como requisito parcial para a obtenção do grau de Mestre em Educação Fisica.

ORIENTADOR: PROF. DR. LUZIMAR RAIMUNDO TEIXEIRA 
Utiyama, Lucilia Kunioshi

Efeitos de um programa de atividades motoras nas variàveis da função pulmonar de idosos / Lucilia Kunioshi Utiyama. - São Paulo: [s.n.], 2000

$x x, 75 p$

Dissertação (Mestrado) - Escola de Educação Fisica e Esporte da Universidade de São Paulo.

Orientador: Prof.Dr. Luzimar Raimundo Teixeira.

1. Condicionamento fisico-Idoso 2. Desenvolvimento motor 3. Pulmões I. Titulo. 


\section{AGRADECIMENTOS}

Este estudo contou com a participação de muitas pessoas que abriram mão do seu tempo para colaborar, oferecendo atenção, dividindo conhecimentos e sabedoria para que pudesse ser concluido. A todas as pessoas que colaboraram direta e indiretamente, meus agradecimentos.

\section{Em especial:}

Agradeço ao meu orientador Prof. Dr. Luzimar Raimundo Teixeira, pela orientação segura e competente. Por ter deixado as portas abertas e possibilitando livre acesso em suas salas de estudo, num convivio quase que diário. Pela confiança, pelo incentivo, pela compreensão, pela incansável paciência, pelo carinho, direcionamento e correções, cujas mãos, mente e coração estiveram juntos na realização deste trabalho.

Aos professores: Décio Barbosa de Souza, Haroldo Marçal e Valdir José Barbanti por terem plantado a semente do Mestrado Interinstitucional entre a Universidade Estadual de Londrina e a Universidade de São Paulo.

Gianna Lepre Perim e Luis Cláudio Stanganelli, em assumir a continuidade deste intercâmbio interinstitucional, com igual competência.

Ao Prof. Dr. Go Tani, pela orientação inicial, sem a qual não seria possivel meu ingresso no programa de pós-graduação.

Ao meu marido Edilson Utiyama, por me aceitar do jeito que sou, me acompanhar de perto na vida pessoal, pelas renúncias e por incentivar meu crescimento profissional. $E$ aos meus filhos Henrique, Alessandra e Jéssica, a quem devo a motivação do meu mestrado, que me envolvem com amor e carinho e preenchem a minha vida.

À você, Débora Beatriz Martins, minha chefe de departamento, companheira e amiga de todas as horas, pela amizade com que sempre me distingüiu e a quem divido esta vitória de mais uma etapa conquistada.

Aos meus pais Aki e Arthur Kunioshi, por serem um exemplo de vida, todo o meu amor. Obrigada pelo carinho, respeito, proteção e dedicação familiar. 
Agradeço à direção da Escola de Educação Física e Esporte da USP, na pessoa do Prof. Dr. Valdir José Barbanti, pela constante preocupação no desenvolvimento dos nossos conhecimentos.

Aos participantes do PIASI, pela enorme contribuição prestada, porque me proporcionaram conviver e compreender melhor as questões do envelhecimento, me possibilitando a permissão e obtenção dos dados deste estudo.

Aos acadêmicos, Magda T. Wladeck, Rubens A. da Silva, Dalva Villela, Adriana S. da Costa, Adriano da Silva e Jemy Nashimoto pelo auxílio nas coletas dos dados e aplicação das atividades na população de estudo e Camila A. Rossi, Michelle Ferla, Márcia D. Torres, Eliane Lima, Rosiwedy R. Silva e Elisângela A. Mello por responderem pelos meus projetos de extensão durante minha ausência.

Agradeço muito à intervenção feita pelas Professoras Silene Sumire Okuma e Cláudia Forjaz, na qualificação deste trabalho, demonstrando dedicação e atenção criteriosa, incentivo e contribuição que possibilitaram a melhoria da qualidade desta dissertação.

Ao Luciano Basso, pela confecção da estatística, revisão e orientações nas análises dos dados, deixando muitas vezes dos seus compromissos para dar prioridade aos meus estudos, pela gentileza com que dividiu seus conhecimentos, por ser responsável pela formatação deste trabalho com tanta dedicação, como se o trabalho também fosse seu.

CEPEUSP - à todos que me honraram com suas amizades, Renata X. Magalhães, Maykell A. Carvalho, José A. Marçal e Cláudia Cezar e Marize. À Fabiane Villa, por ter me recebido em seu laboratório, pelos ensinamentos técnicos e auxílio na aplicação das provas de espirometria e pico de fluxo expiratório com muita paciência e responsabilidade, graça e simpatia junto aos idosos do Programa, pelas quais a admiro.

À Sônia A. dos Santos, secretária do Programa de Asma, pela prontidão no atendimento e valiosas contribuições dadas no decorrer do trabalho e principalmente pela amizade que foi fundamental para o periodo de estágio na USP.

À professora Tiemi Matsuo (HU/Londrina), pelo auxílio nos esclarecimentos quanto a aplicação da estatística mais adequada para este estudo.

Para Célia, Maria de Lourdes e Abel da secretaria da Pós graduação da EEFUSP, agradeço a atenção e eficiência nos atendimentos prestados.

Aos funcionários da biblioteca da EEFUSP, pela prontidão no atendimento e sobretudo à Maria Lúcia V. Franco, pelo auxílio nas correções finais da formatação do texto. 
Luis Cláudio Stanganelli e Antônio Carlos Dourado, por cederem o espaço do Laboratório CENESP/UEL e pela assessoria prestada nos periodos das coletas de dados.

Marcos Cesar Clares, técnico do Laboratório LADESP/USP, obrigada por me atender à qualquer hora, por ser tão eficiente em tudo o que faz.

À minha cunhada Simone, pela generosa acolhida que sempre me proporcionou durante o período de mestrado, dividindo seu espaço e me permitindo estar "em casa".

A minha irmã Nilce, por cuidar sempre de mim e de minha família e ser muitas vezes, mãe dos meus filhos. Por ser meu "espelho" como profissional.

Aos meus irmãos, cunhadas(os), não citados nominalmente mas que são muito importantes porque sempre estiveram presentes em minha vida.

Meus mais profundos agradecimentos aos companheiros do mestrado: Gianna, Kátia, Denilson, Sérgio, Ernani, Gladys, Cristiane, Juvenilson, Hélio, Dourado, Marquinhos e Pedro porque juntos e entre textos, crescemos profissionalmente e fortalecemos nossa amizade. Kátia e Gi, pelo apoio, pela amizade e pelos desafios que juntas enfrentamos.

Amigas Rosa, Maria Cláudia e "PI", que nos conquistaram de um jeito especial e passaram a fazer parte do nosso grupo.

Ao professor e amigo Denilson, companheiro de estrada, que transformou minhas idas à São Paulo mais fáceis e que através deste mestrado se tornou quase irmão.

Ao Wanderley Polly (CEFD/UEL) e demais funcionários do Centro, obrigada.

Abdalah Achour Júnior (Revista Brasileira de Atividade Física \& Saúde), que sempre me incentivou a transformar meus pensamentos em textos. Agora, recebe meu artigo para publicação na revista

Ao Prof. Dr. Wilson Jacob Filho e Prof $\mathrm{Dr}^{a}$ Silene, pelas reflexões e contribuições feitas na banca de defesa.

À academia LITTERA (Kilda e Viviane), pelas aulas de inglês e pelo abstract.

À DEUS, por ter me dado a dádiva da vida, dedico a minha existência, pois tudo o que faço e acredito veio do Senhor.

\section{Em memória}

Prof. João Santana, exemplo de fé no Senhor, de persistência, resignação e luta por uma vida com mais amor, registro aqui as minhas saudades. 


\section{SUMÁRIO}

LISTA DE TABELAS ……............................................................... vii

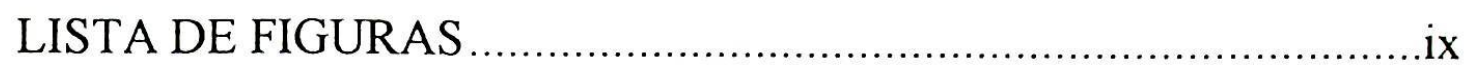

LISTA DE SÍMBOLOS E DEFINIÇÕES DE TERMOS ......................

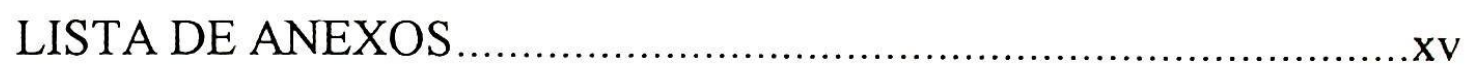

LISTA DE APÊNDICES .................................................................

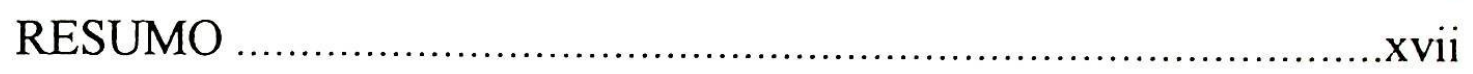

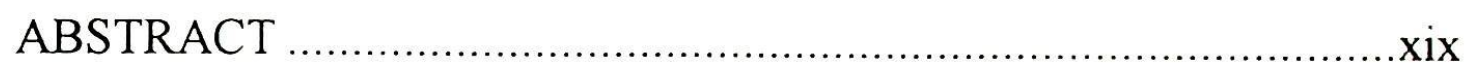

INTRODUÇÃO

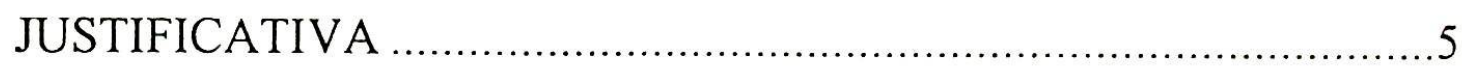

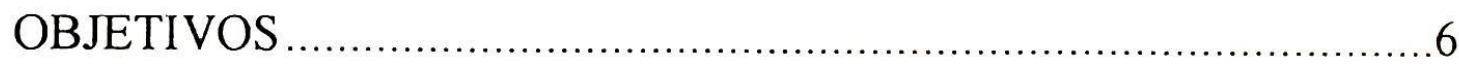

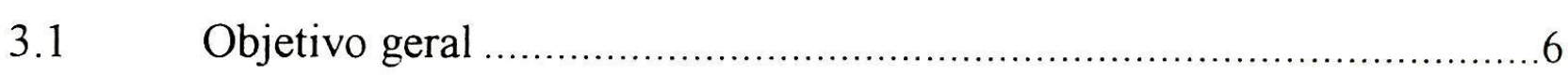

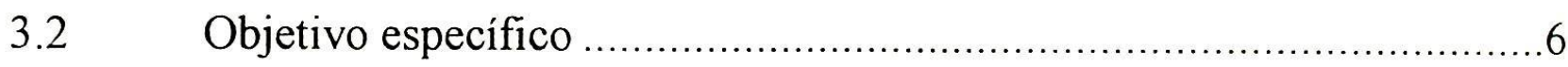

4 QUESTÃO A SER INVESTIGADA …………………………....6

$5 \quad$ REVISÃO DE LITERATURA ……................................................

5.1 Os efeitos do processo de envelhecimento no sistema respiratório .......7

$5.2 \quad$ Pulmão em envelhecimento .......................................................9

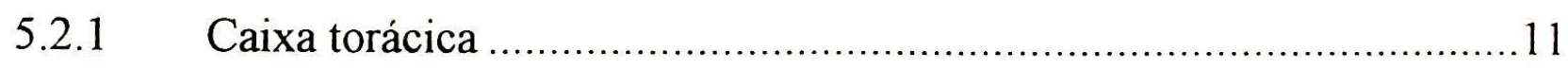

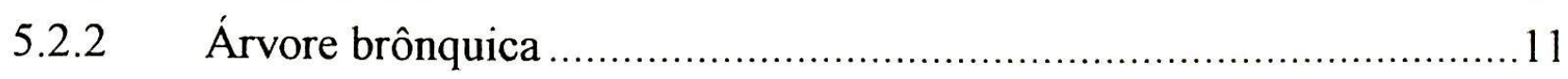

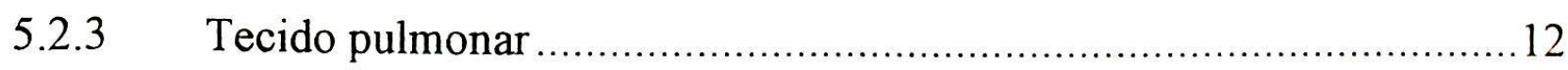

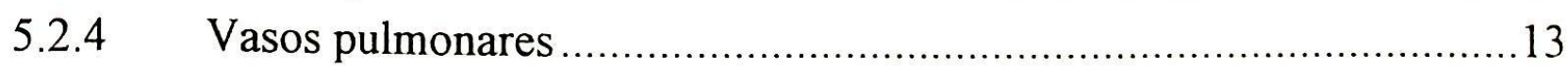

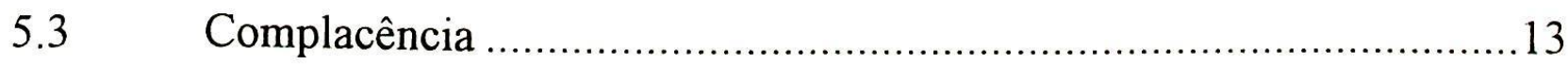

5.3.1 Complacência da caixa torácica ....................................................13

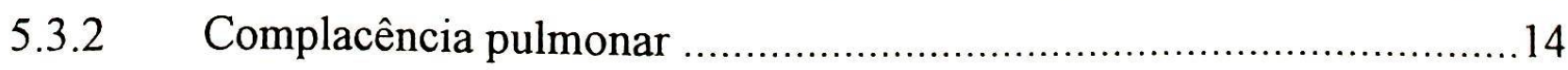

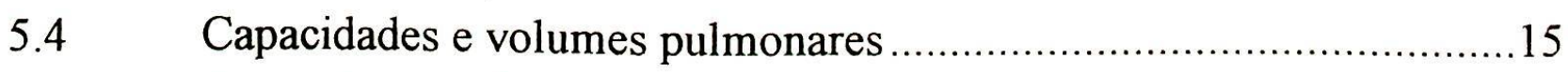

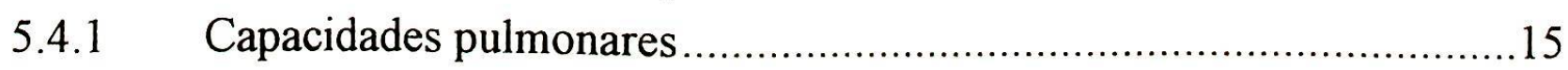

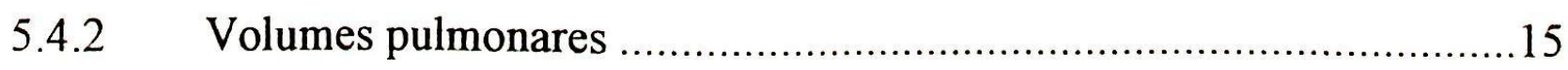

5.4.3 Volumes pulmonares estáticos ......................................................17 


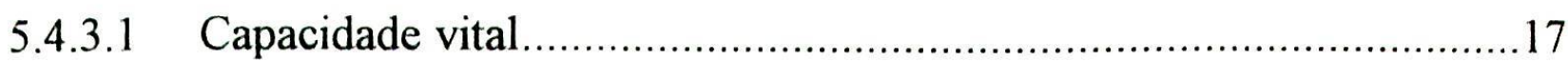

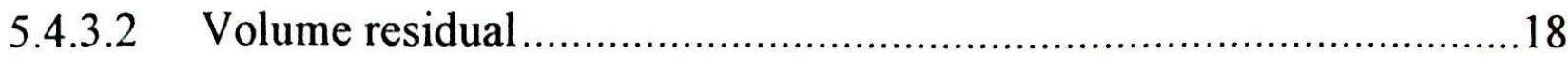

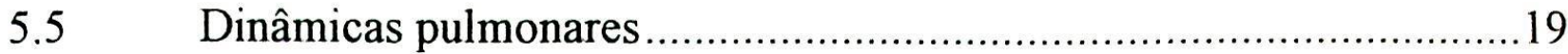

5.5.1 Performance do músculo respiratório ............................................19

5.5.2 Colapso e impedância das vias aéreas ............................................20

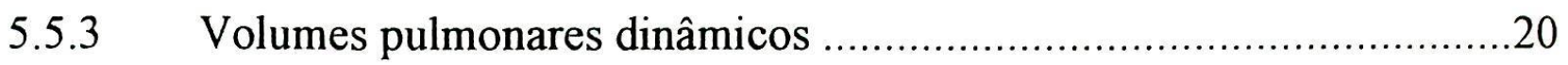

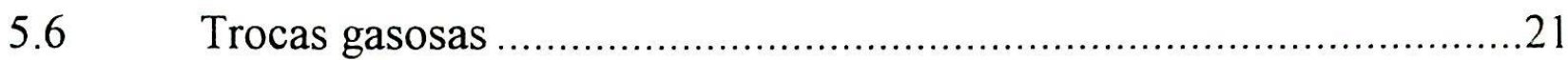

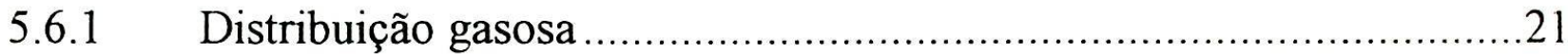

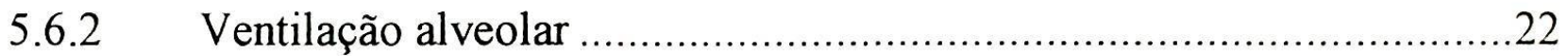

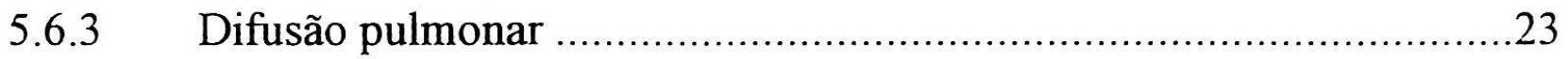

5.6.4 Gradientes de pressão alveolar-arterial ..........................................24

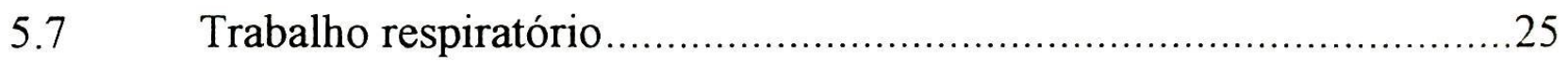

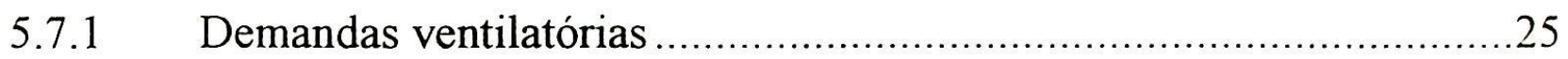

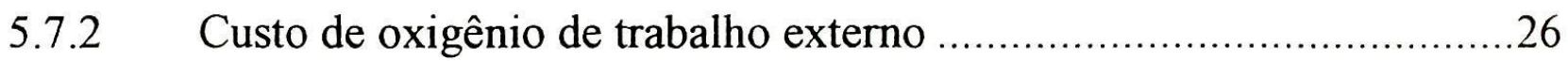

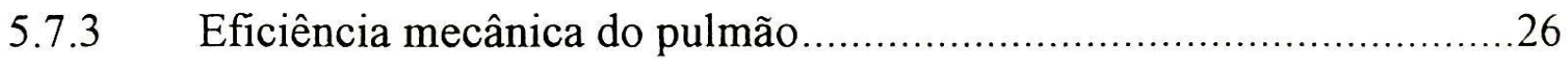

5.7.4 Custo de oxigênio do trabalho respiratório .....................................27

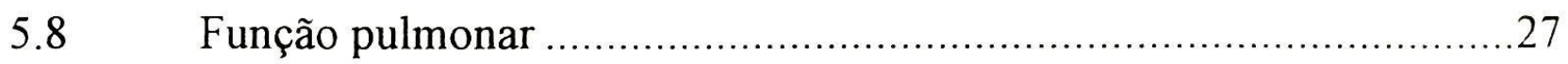

5.9 Os efeitos da atividade motora na função pulmonar de idosos ..........28

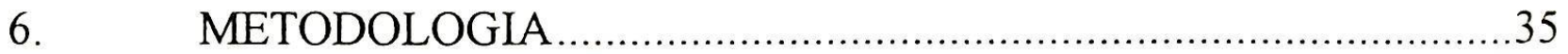

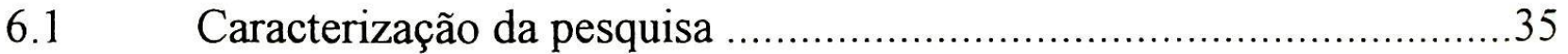

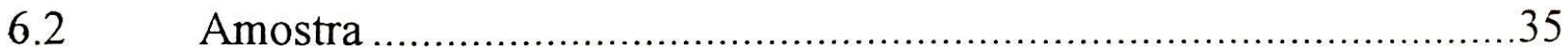

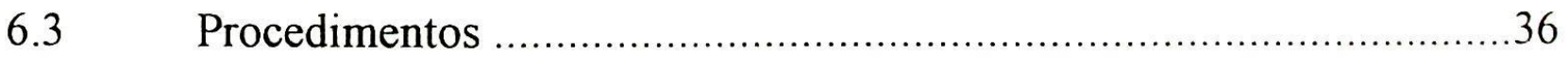

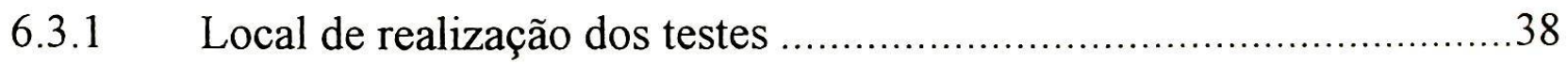

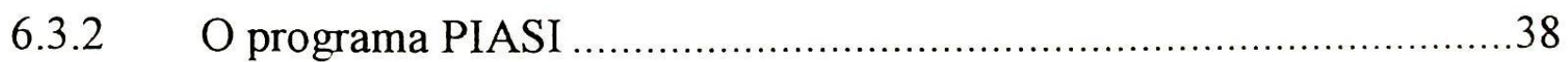

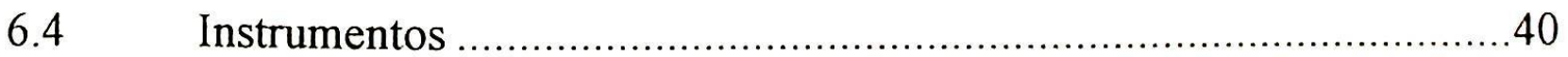

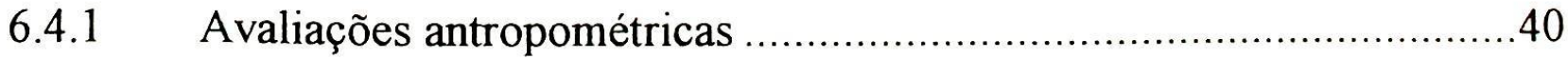

6.4.2 Medição da função pulmonar ............................................................ 41

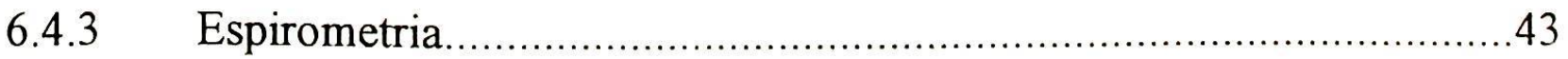

6.4.3.1 Espirometria simples ou convencional ........................................45

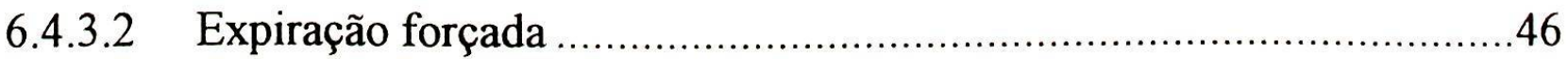

6.4.4 Monitor de pico de fluxo expiratório (peak-flow) ...........................47

6.4.5 Medidas do pico de fluxo expiratório (peak-flow)...........................48 


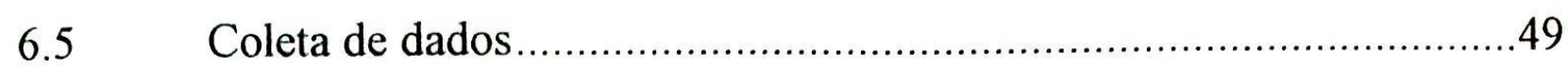

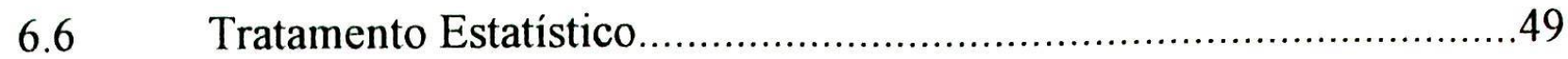

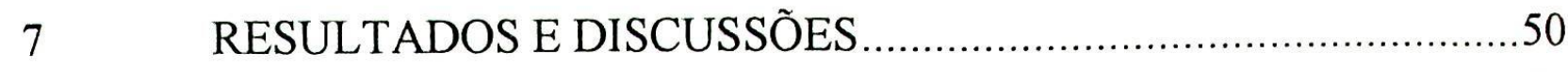

7.1 Análise da medida do pico de fluxo expiratório ..............................56

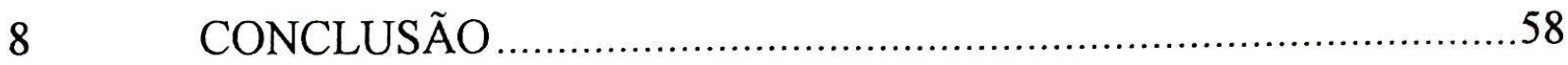

REFERÊNCIAS BIBLIOGRÁFICAS .......................................60

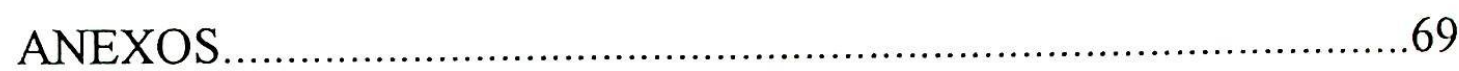

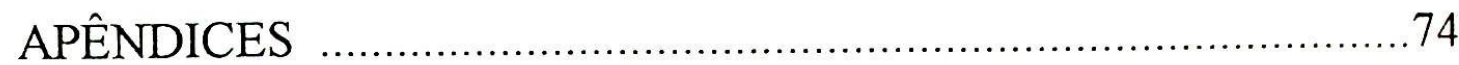




\section{LISTA DE TABELAS}

Página

TABELA 1 - Média e desvio padrão, valor do teste " $t$ " de Student e valor do "p" para as variáveis $\mathrm{CVF}, \mathrm{FEV}_{1}, \mathrm{PEF}$ e $\mathrm{FEF}_{25-75 \%}$ dos grupos experimental e comparativo. 


\section{LISTA DE FIGURAS}

Página

FIGURA 1 - Nível de alteração entre pré e pós-intervenção nas variáveis do estudo dos grupos experimental e comparativo (expressos em porcentagem)

FIGURA 2 - Distribuição dos participantes de acordo com as alterações ventilatórias encontradas nas provas de pico de fluxo expiratório na pré-intervenção

FIGURA 3 - Valores médios (média) do pico de fluxo expiratório em cada um dos momentos (12 avaliações mais a avaliação do pósintervenção) do grupo experimental. 


\section{LISTA DE SÍMBOLOS E DEFINIÇÕES DE TERMOS}

Para a compreensão desse estudo, alguns termos e símbolos deverão ser entendidos de acordo com as definições utilizadas em espirometria e publicadas pela Sociedade Brasileira de Pneumologia e Tisiologia (1996), tais como:

\section{Volume Residual (VR)}

Volume de ar que ainda permanece no pulmão, depois de profunda expiração.

\section{Volume de Inspiração Respiratória (VIR)}

Volume de ar que é exigido com cada inspiração, com respiração calma.

\section{Volume de Reserva Inspiratória (VRI)}

Volume de ar que ainda pode ser aspirado através de inspiração máxima, depois da inspiração normal.

\section{Volume de Reserva Expiratória (VRE)}

Volume de ar que ainda pode ser expelido, através de expiração máxima, depois da expiração normal. 


\section{Capacidade Vital (CV)}

Volume de ar que pode ser expirado ao máximo, depois de inspiração máxima. Corresponde à soma de VIR + VRI + VRE. Esta grandeza é expressa em litros nas condições de temperatura corporal $\left(37^{\circ} \mathrm{C}\right)$, pressão ambiente e saturado de vapor de água.

\section{Capacidade Vital Forçada (CVF)}

Representa o volume máximo de ar exalado com esforço máximo, a partir do ponto de máxima inspiração. É um teste muito dependente do esforço e pode ser reduzido devido à falta de cooperação do paciente.

\section{Capacidade Total (CT)}

Conteúdo de ar o maior possível, depois de inspiração profunda máxima. Corresponde à soma de VIR + VRI + VRE + VR.

\section{Volume Expiratório Forçado (VEF/FEV)}

É o volume de ar exalado no primeiro segundo de uma expiração forçada máxima.

\section{Volume Expiratório Forçado em 1 segundo $\left(\mathrm{VEF}_{1} / \mathrm{FEV}_{1}\right)$}

É o volume de ar que é expelido no primeiro segundo da expiraçâo forçada. Permanece sendo o melhor método de mensuração da gravidade da obstrução das vias aéreas. É relativamente independente do esforço uma vez que o indivíduo realiza uma tentativa razoável de expelir o ar rapidamente. Deve ser comparado com o valor predito que geralmente é fornecido na impressão dos resultados pelo espirômetro. Uma relação reduzida $\mathrm{FEV}_{1} / \mathrm{CVF}(<75 \%)$ é geralmente considerada como um índice da gravidade da obstrução das vias aéreas. 


\section{Fluxo Expiratório Forçado (FEF)}

É a taxa de fluxo médio medida durante a metade do meio da expiração.

\section{Pico de Fluxo Expiratório (PFE/PEF)}

Representa o fluxo máximo de ar durante a manobra de capacidade vital forçada. Esta grandeza é expressa em litros/segundos. Este é o teste de função pulmonar mais simples e também pode ser medido através de simples aparelhos no domicílio. É muito dependente do esforço, mas bastante reprodutível em indivíduos que cooperam totalmente com o teste. O PEF reflete principalmente a gravidade da obstrução nas vias aéreas maiores.

\section{Fluxo expiratório forçado entre $25 \%$ a $75 \%\left(\mathrm{FEF}_{25-75 \%}\right)$}

Fluxo expiratório forçado expelido e algumas vezes calculado como alteração do volume entre $25 \%$ e $75 \%$ do CVF, dividido pelo tempo tomado para esta alteração volumétrica $\left(\mathrm{FEF}_{25-75 \%}\right)$. Este parâmetro é amplamente independente do esforço e reflete, principalmente, a gravidade da obstrução das pequenas vias aéreas. É uma medição importante uma vez que ela pode estar bem anormal quando o PEF e mesmo o $\mathrm{FEV}_{1}$ estão normais.

\section{Monitor de Pico de Fluxo (Wright Peak-Flow Meter)}

O monitor de pico de fluxo expiratório mede a velocidade de saída do ar dos pulmões (em litros por minuto). 


\section{Aptidão física}

Segundo MATSUDO \& MATSUDO (1992), "é a capacidade que um individuo tem para desempenhar as funções cotidianas a que se propõe, sem desequilíbrio de sua integridade biológica, psicológica e social."

\section{Atividade física}

A expressão atividade física também não tem um entendimento consensual, embora venha sendo, por alguns, conceituada como "qualquer movimento humano produzido pelos músculos esqueléticos resultando em substancial aumento de dispêndio de energia." (BOUCHARD \& SHEPHARD, 1993; FARIA JUNIOR.\& RIBEIRO, 1995).

\section{Exercício físico}

Segundo as acepções mencionadas no Dictionary of Science (FARIA JUNIOR.\& RIBEIRO, 1995), é entendido como forma de movimento humano para atingir um dos seguintes objetivos: manter um certo nível da função física, desenvolver capacidades físicas funcionais, restaurar alguma perda da capacidade funcional e desenvolver novas capacidades funcionais para compensar a perda de outras anteriormente existentes. Como se observa as duas primeiras acepções vinculam-se à idéia do que alguns autores chamam de atividade fisica, enquanto as duas últimas estão mais ligadas à idéia de exercícios terapêuticos.

\section{Atividade motora}

Neste estudo o termo atividade motora será utilizado como sinônimo de exercício. Portanto, pode ser entendido como uma forma de atividade fisica, normalmente realizada por um longo período de tempo, com objetivos específicos a serem atingidos como aumento da aptidão fisica ou da saúde. É fundamentada 
nos princípios do treinamento referentes ao tipo de atividade, intensidade, freqüência e duração.

\section{PIASI}

Programa Interdisciplinar de Assistência à Saúde do Idoso. Este programa é um projeto de extensão que assiste o idoso que busca atendimento no Hospital das Clínicas da Universidade Estadual de Londrina - Paraná. 


\section{LISTA DE ANEXOS}

Página

ANEXO I - Ficha individual da história clínica.......................................69

ANEXO II - Ficha individual da avaliação pulmonar ................................. 71

ANEXO III - Dados do sexo, idade, altura, peso dos indivíduos dos grupos comparativo e experimental, resultados obtidos no pré e pósintervenção do programa de atividades motoras nas variáveis CVF, $\mathrm{FEV}_{1}$, PEF e $\mathrm{FEF}_{25-75 \%}$ e a porcentagem de alteração entre pré e pós para cada variável $(\Delta)$ 


\section{LISTA DE APÊNDICES}

Página

APÊNDICE 1 - Aprovação do comitê de bioética do Hospital Universitário de Londrina - Paraná ..................................................... 74

APÊNDICE 2 - Termo de Consentimento................................................ 75 


\section{RESUMO}

\section{EFEITOS DE UM PROGRAMA DE ATIVIDADES MOTORAS NAS VARIÁVEIS DA FUNÇÃO PULMONAR DE IDOSOS}

\section{Autora: LUCILIA KUNIOSHI UTIYAMA Orientador: PROF. DR. LUZIMAR RAIMUNDO TEIXEIRA}

O objetivo deste estudo foi investigar e documentar os efeitos de um programa de atividades motoras nas variáveis da função pulmonar de idosos. Foram avaliadas as variáveis: capacidade vital forçada (CVF), volume expiratório forçado em 1 segundo $\left(\mathrm{FEV}_{1}\right)$, pico de fluxo expiratório (PEF) e fluxo expiratório forçado entre 25 a 75\% (FEF25-75\%) da capacidade vital forçada, através da espirometria e monitor de pico de fluxo expiratório. A amostra foi composta por 33 sujeitos, de ambos os sexos, divididos em grupo comparativo $(n=12)$ e grupo experimental ( $\mathrm{n}=21)$. A idade média dos participantes foi de 76,4 anos, integrantes do Programa Interdisciplinar de Assistência à Saúde do Idoso do Hospital das Clínicas da Universidade Estadual de Londrina - Paraná. O programa de atividades motoras teve uma sessão semanal de 60 minutos, durante 12 semanas. Os dados foram coletados utilizando o monitor de pico de fluxo (semanalmente) e espirômetro (pré e pós-intervenção do programa). Os dados da espirometria foram tratados utilizando a estatística descritiva (média e desvio-padrão), as diferenças percentuais entre o pré e pós-intervenção foram constratadas mediante o teste " $\mathrm{t}$ " 
de Student, para amostra independentes, com um número de elementos diferentes. Para analisar a variável pico de fluxo expiratório (PEF), utilizou-se do teste de Análise de Variância para medidas repetidas (Anova one way), que mostrou haver diferença significativa $(\mathrm{F}[12,132]=2,9985, \mathrm{p}=0,001)$; seguido do teste de Post hock de Tuckey. Os resultados da espirometria apresentaram um aumento nos valores médios tanto para o grupo comparativo quanto para o grupo experimental

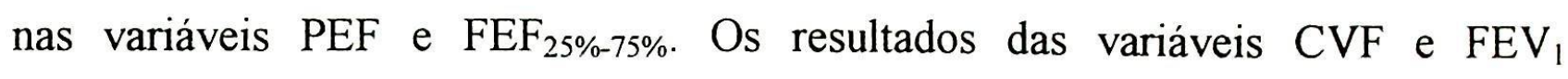
apresentaram declínio após o período do programa de atividades motoras. A avaliação espirométrica foi também importante na identificação dos quadros de obstruções das vias aéreas, podendo contribuir para a orientação dos procedimentos em programas de atividades e reeducação da mecânica respiratória dessa população.

Palavras chaves: atividade motora, envelhecimento, função pulmonar. 


\begin{abstract}
EFFECTS OF A PROGRAM OF MOTOR ACTIVITIES ON THE VARIABLES OF THE PULMONARY FUNCTION OF THE ELDERLY
\end{abstract}

\author{
Author: LUCÍLIA KUNIOSHI UTIYAMA \\ Adviser: PROF. DR. LUZIMAR RAIMUNDO TEIXEIRA
}

The objective of this study was to investigate and document the effects of a program of motor activities on the variables of the pulmonary function of the elderly. Variables were assessed through spirometry and the wright peak flow meter: forced vital capacity (CVF), 1-second forced expiratory volume $\left(\mathrm{FEV}_{1}\right)$, expiratory flow peak (PFE) and forced expiratory flow from $25-75 \%\left(\mathrm{FEF}_{25-75 \%}\right)$ of the forced vital capacity. The study involved 33 male and female subjects, with a mean age of 76.4, who take part of the Interdisciplinary Program of Health Assistance at the Clinics Hospital in the City of Londrina - Paraná. They were divided into two groups: a comparative group $(n=12)$ and an experimental one $(n=$ 21). The program of motor activities took place once a week during 60 minutes for 12 weeks. The data were collected with a wright peak flow meter (weekly) and a spirometer (before and after the program intervention). In order to analyse the data from the spirometry was used the descriptive statistics (mean and standard deviation) and test " $t$ " to observe the percentile differences before and after the intervention for the independent samples with a number of different elements. 
Anova One Way and Post Hock Tuckey tests were used to analyse the expiratory flow peak which showed meaningfyl diference $([\mathrm{F} 12,132]=2,9985, \mathrm{p}=0,001)$. The results from spirometry showed increasing median value for both comparative and experimental groups on the variables $\mathrm{PFE}$ and $\mathrm{FEF}_{25-75 \%}$. The value of $\mathrm{CVF}$ and $\mathrm{FEV}_{1}$ decreased after the program of motor activities. There were meaningful differences on the median value of PFE by indicating improvement. The spirometer evaluation was also important to identify obstruction of the airways and it can contribute to guide the procedures for the program de activities and to reeducate the respiratory mechanics of the elderly.

Key words: motor activity, aging, pulmonary function. 
A questão da velhice diz respeito à sociedade como um todo. Não se destina somente aos já idosos, mas também aos jovens que serão os futuros idosos. A problemática do envelhecimento populacional é, antes de científica, uma questão social inserida numa realidade cada vez mais complexa. O fenômeno do envelhecimento é ao mesmo tempo antigo para a humanidade, mas novo para a sociedade moderna.

As condições que envolvem o processo de envelhecimento não é uma particularidade de um ou outro indivíduo; é formação de uma realidade mundial.

Um fator determinante para o envelhecimento populacional diz respeito às transições decorrentes de mudanças nos níveis de mortalidade e fecundidade. Observa-se isto na queda da mortalidade e na redução da natalidade. Essa diminuição da taxa de mortalidade está relacionada à mudança do comportamento em relação à saúde, pela contribuição do estilo de vida saudável e do ambiente na prevenção das enfermidades, que leva a um aumento da expectativa de vida (BERQUÓ, 1996).

SCHOUERI JÚNIOR, RAMOS \& PAPALÉO NETTO (1994) citam que o aumento na expectativa de vida da população mundial está intimamente ligado à melhoria das condições de vida e de atenção à saúde. A ciência tem buscado descobrir as virtudes da velhice e prolongar o tempo de vida da população. $\mathrm{O}$ aumento da expectativa de vida humana tem resultado em um número crescente de pessoas que atingem ou ultrapassam os 65 anos. Deve-se levar em consideração também a migração como um outro fator, cuja importância é relativa, mas que ajuda a alterar a distribuição etária.

Enquanto a população mundial cresce por volta de 1,7\% ao ano, a faixa da população com mais de 60 anos aumenta mais de 2\% (GOBBI, 1997). 
Dados estatísticos com referência às transições demográficas mostra que a pirâmide de antiga base larga, representando a população de jovens, atualmente passa a ter base arredondada. A tendência em direção a uma sociedade mais idosa parece ser universal.

No Brasil, a pirâmide era constituída por jovens até meados de 1970, na atualidade constata um número de idosos considerável e crescente (BRASIL, Ministério da Justiça,1998). As investigações nesse sentido indicam que a nossa população de idosos vem crescendo significativamente, com previsão de maior crescimento ainda em futuro próximo (SCHOUERI JÚNIOR et al., 1994).

São considerados idosos os indivíduos acima de 65 anos de idade, porém, segundo publicações da OMS - Organização Mundial de Saúde (1984) citado pelo IBGE (1987), essa idade foi diminuída em alguns países em desenvolvimento. No Brasil, considera-se idoso os indivíduos acima dos 60 anos (ROCHA \& MAZO, 2000). Isto é justificado pela quantidade de pessoas que conseguem atingir faixas etárias mais elevadas em algumas regiões e pelas próprias características anatômicas e fisiológicas desses grupos, ligadas intimamente aos fatores sociais, econômicos e culturais (KOPILER, 1997).

No ano de 2025 os habitantes com 60 anos ou mais comporão, numa estimativa conservadora, um contingente de 31,8 milhões de pessoas, o que situará o Brasil como o sexto país do mundo em termos de população de idosos (MATSUDO, 1997b; SCHOUERI JÚNIOR et al., 1994; VERAS, 1994). Isso faz com que se perceba essa realidade como prioridade em nossa sociedade.

Segundo HAYFLICK (1996), o envelhecimento parece ser um produto da civilização. O ser humano só está conseguindo viver mais graças aos avanços tecnológicos que permitiram eliminar grande parte das adversidades que ameaçam a vida humana. Com este sucesso o homem passa a ser obrigado a experimentar as mudanças biológicas associadas ao envelhecimento. 
O ano de 1999 é considerado o "Ano Internacional do Idoso" e, segundo GUIMARÃES ${ }^{1}$, o próximo século será o século da velhice. Em que todos nós porque todos nós vamos envelhecer. A única alternativa para não envelhecer é morrer jovem, o que nenhum de nós deseja.

Segundo HAYFLICK (1996), antes de se buscar uma vida longa é necessário investir na qualidade de vida das pessoas, e se possível for, obter a longevidade com qualidade. Com esse raciocínio ele cria o conceito de "expectativa de vida ativa, saudável ou funcional", no qual a expectativa de vida ativa termina quando a saúde de uma pessoa se deteriora a ponto de provocar a perda de sua independência, precisando de algum tipo de assistência.

PESCATELLO \& DI PIETRO (1993) ressaltam que aproximadamente $80 \%$ das pessoas acima de 65 anos apresentam ao menos um problema crônico de saúde, demonstrando limitações físicas e motoras que os anos lhe impõem.

Com a era da modernidade tecnológica e da revolução industrial, observa-se uma notável transformação na sociedade. Os trabalhadores rurais e fisicamente ativos foram substituídos por indivíduos aposentados e sedentários, com um estilo de vida de relativo conforto, favorecidos pelos equipamentos e maquinários automáticos avançados. A inatividade física e o aumento do sedentarismo, associados a outros fatores e hábitos de vida, provocam sérias mudanças no corpo e distúrbios funcionais.

Não está bem caracterizado o momento em que ocorre o declínio das capacidades orgânicas, já que o processo de envelhecimento depende mais da idade biológica das pessoas do que da cronológica. O certo é que ocorre um declínio nas funções de todos os sistemas orgânicos.

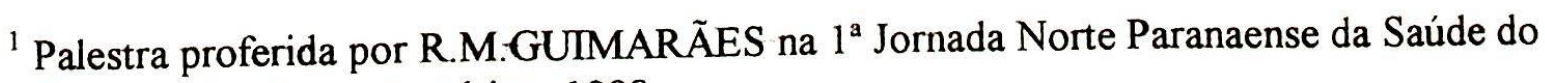
Idoso, realizada em Londrina, 1998. 
No pulmão, a capacidade vital e o volume residual são afetados pelo processo de envelhecimento. O pulmão diminui em elasticidade resultando em uma diminuição da capacidade de expirar, limitando a oxigenação sangüínea e dificultando o seu funcionamento durante exercícios físicos vigorosos devido à grande carga de trabalho necessário para o nível dessa oxigenação.

A nossa atenção voltou-se principalmente para estas questões que se relacionam com a capacidade pulmonar em uma idade avançada, uma vez que muitos problemas respiratórios ocorrem no idoso, apresentando sintomas como a tosse, falta de ar, fadiga e dor de estômago, e que resultam na utilização mais freqüente de serviços médicos. Para a prevenção desses problemas um dos fatores que deve ser levado em conta é a atividade fisica orientada. Encontram-se na literatura diferentes formas de mostrar que a atividade fisica interage para uma melhor função do organismo idoso e altera todo seu estilo de vida para obter bons hábitos de saúde, com intervenções preventivas e corretivas adequadamente planejadas, como os programas de atividades motoras, que podem prevenir, retardar ou mesmo minimizar algumas das alterações/restrições no sistema respiratório. É imprescindível adotar medidas de caráter preventivo, para evitar o crescimento da população de idosos doentes e dependentes.

Estudos de MATSUDO (1997a) verificaram uma diminuição da incidência das enfermidades quando adotados comportamentos positivos em relação à saúde, dentre eles, o estilo de vida ativo.

A Educação Física é uma das profissões que tem um papel importante frente a esta temática, já que também trabalha diretamente com a atividade motora e a qualidade de vida das pessoas.

Nos últimos cinco anos, preocupada com os altos índices de atendimento ao idoso nos hospitais vinculados, a Universidade Estadual de Londrina (UEL) vem mantendo projetos de extensão na assessoria e 
atendimento gerontológico à comunidade. Nestes programas atuam de maneira integrada geriatra, médica sanitarista, cardiologista, fisioterapeuta, assistente social, bioquímico, enfermeira, psicóloga, arte-terapêuta e profissionais de educação física. A solicitação de profissionais de educação física nesses projetos se deu pela necessidade de conscientizar os idosos do programa sobre a importância da prática da atividade física, bem como orientar as atividades motoras regulares como forma de inibir o sedentarismo. Nesta pesquisa, o enfoque principal será verificar o quanto um programa de atividades motoras orientadas pode trazer de mudanças nas variáveis de função pulmonar dos idosos participantes do projeto de extensão PIASI. Ainda que os vários componentes da função pulmonar sejam discutidos como entidades separadas, é importante enfatizar que o corpo funciona como um todo e muitas vezes o que afeta um sistema terá também um efeito sobre o todo.

\section{JUSTIFICATIVA}

A elaboração deste projeto de pesquisa surgiu da necessidade de verificar se um programa regular de atividades motoras orientadas aplicadas ao idoso, uma vez por semana, pode promover mudanças nas variáveis da função pulmonar. Além disso, a partir dos resultados obtidos, analisar juntamente com os demais profissionais da equipe multidisciplinar, a atuação semanal da Educação Física no PIASI.

Embora muitos estudos tenham investigado a relação entre atividade física e as questões relacionadas ao envelhecimento, ainda são necessárias mais investigações que verifiquem as influências das atividades motoras na função pulmonar da população idosa. Torna-se indispensável a produção e disseminação de novos conhecimentos relacionados a esta temática. 


\section{OBJETIVOS}

\subsection{Objetivo geral}

Investigar e documentar os efeitos de um programa regular de atividades motoras nas variáveis da função pulmonar de idosos, participantes do Projeto PIASI.

\subsection{Objetivo específico}

Verificar os efeitos de 12 semanas de intervenção de um programa de atividades motoras, nas variáveis $\mathrm{CVF}, \mathrm{FEV}_{1}, \mathrm{PEF}$ e $\mathrm{FEF}_{25-75 \%}$ da função pulmonar dos idosos do PIASI e através dos resultados da espirometria e pico de fluxo expiratório, analisar os estados iniciais e final da condição respiratória de cada participante.

\section{QUESTÃO A SER INVESTIGADA}

Um programa regular de atividades motoras orientadas pode modificar variáveis da função pulmonar de idosos? 
A revisão de literatura será conduzida buscando enfocar as definições, breve histórico e explicações gerais sobre o assunto do estudo em questão.

\section{Os efeitos do processo de envelhecimento no sistema respiratório}

Neste estudo, serão apresentados alguns importantes aspectos relacionados aos efeitos do processo de envelhecimento no sistema respiratório, e que podem apresentar possíveis implicações em programas de atividades motoras.

Muitas mudanças são acarretadas pelo processo de envelhecimento e podem apresentar limitações físicas e motoras, prejudicando a autonomia do idoso. Como todas as outras fases da vida o envelhecimento apresenta mudanças orgânicas. Segundo NERI (1995), há evidências de que existe um declínio linear na maioria das reservas funcionais dos sistemas do corpo, sendo acentuado em pessoas sedentárias.

De acordo com WEINECK (1991), as alterações que ocorrem com o idoso, tanto em termos estruturais como funcionais, são responsáveis pela redução do desempenho e da performance motora na idade avançada.

Os declínios que ocorrem referem-se a menor tolerância ao estresse, resistência física, tempo de reação, cognição, resistência imune, ingestão e absorção de nutrientes, audição, visão, função cardiovascular, diferenciação celular e eficiência respiratória (BOTH, 1994). Em parte essas alterações orgânicas são próprias do envelhecimento, mas os hábitos inadequados durante a vida prejudicam os determinantes básicos da saúde. 
A maioria dos efeitos do envelhecimento ocorre por imobilidade e má adaptação e não por doenças crônicas. Em verdade, com o avançar da idade nos tornamos mais propensos a desenvolver doenças crônicas.

A velhice deve ser dissociada da doença. Na verdade, não é o envelhecimento por si só que causa a doença. O organismo do idoso se torna mais vulnerável às doenças devido às suas perdas funcionais, e à menor capacidade de combatê-las, mas definitivamente o envelhecimento não pode ser confundido como doença e essas doenças não fazem parte do processo normal de envelhecimento (BEAUVOIR, 1990; HAYFLICK, 1996; NERI, 1993).

Para MATSUDO \& MATSUDO (1992), todas as mudanças morfológicas e funcionais que acontecem com o decorrer da idade podem ser devidas à conjunção de três fatores: fenômeno do envelhecimento, presença de doença e estilo de vida sedentário. Porém, alguns gerontólogos acreditam que $50 \%$ do envelhecimento é devido a um estilo de vida sedentário, que é responsável pela diminuição da capacidade física.

As implicações funcionais de uma idade avançada estão associadas também com a redução da capacidade respiratória. Faz parte do sistema respiratório o trato respiratório superior (nariz, faringe, laringe) e trato respiratório inferior (traquéia, brônquios, pulmão), cujas funções são o olfato, o transporte, filtração, umedecimento e o aquecimento do ar que respiramos e que são fundamentais para a manutenção da homeostase do organismo.

O sistema respiratório se deteriora progressivamente com a idade e as doenças respiratórias, como a bronquite, asma, câncer do pulmão, pneumonia e a insuficiência pulmonar, contribuem para reduzir ainda mais a função respiratória.

De acordo com SMITH \& GILLIGAM (1984), com relação à função pulmonar, há diminuição de 40 a $50 \%$ da capacidade vital e aumento de 30 a $50 \%$ do volume residual respiratório. 
Alguns dos efeitos deletérios do envelhecimento relativos ao pulmão ocorrem com a diminuição da capacidade vital, aumento do volume residual, do espaço morto anatômico e da ventilação durante o exercício, diminuição da capacidade de difusão pulmonar e da menor mobilidade da parede torácica (MATSUDO, 1997a; WEINECK, 1991).

\subsection{Pulmão em envelhecimento}

O pulmão é o órgão mais importante do aparelho respiratório. É semelhante a uma esponja e é constituído por milhões de alvéolos. Estes são formados por uma membrana de células delicadas e finas que separa o ar dos alvéolos de uma rede de vasos sangüíneos. O pulmão está no início e no fim do processo vital, onde a circulação sangüínea representa um papel central.

Além desta superficie de trocas gasosas, existe um sistema de tubos (traquéia, brônquios e bronquíolos) que leva o ar do meio ambiente para os alvéolos e vice-versa. A maior parte das vias aéreas é circundada por uma faixa de músculo, que tem função protetora, de maneira que se um gás potencialmente tóxico é inalado, esta musculatura se contrai para impedir sua entrada nos pulmões.

A principal função dos pulmões é prover uma superfície ampla para que o oxigênio do ar possa difundir-se para o sangue e ser levado às outras partes do corpo. Ao mesmo tempo, o gás carbônico produzido pelas células do corpo é trazido pelo sangue venoso e expelido para fora durante a expiração. $\mathrm{O}$ ar entra pelo nariz onde é umidificado, aquecido e filtrado para não danificar as vias aéreas inferiores (brônquios e bronquíolos). É posteriormente conduzido até a traquéia e brônquios. Estes vão se ramificando em tubos cada vez mais estreitos, curtos e numerosos até chegarem aos alvéolos, onde ocorrem as trocas gasosas. 
A capacidade total (CT) dos pulmões apresenta pouca diminuição com o aumento da idade, mas com o processo de envelhecimento ocorre uma acentuada regressão da capacidade vital (CV) e do volume residual (VR), acarretando mudanças no tecido pulmonar diminuindo sua elasticidade, resultando em uma diminuição da capacidade de expirar e em volume residual (VR) aumentado.

Segundo WEINECK(1991), o pulmão em envelhecimento caracteriza-se por uma dilatação dos alvéolos e uma diminuição do número de alvéolos com as alterações correspondentes na estrutura de fibras.

O mesmo autor cita que, através da diminuição do número de alvéolos, ocorre uma diminuição da superfície total respiratória; através do deslocamento da parcela solúvel do colágeno, favorecendo a parcela não solúvel, ocorre uma redução da elasticidade do pulmão. O engrossamento da membrana basal dos capilares do pulmão leva a uma diminuição da permeabilidade dos capilares alveolares. Pela diminuição da capacidade do pulmão com a idade, no entanto, não são responsáveis apenas causas intrapulmonares, mas também extrapulmonares. Uma vez que para a função do pulmão, a mobilidade de toda a caixa torácica é decisiva, a ossificação da cartilagem das costelas, condicionada ao envelhecimento e às alterações da coluna vertebral, leva a uma limitação da capacidade de dilatação do tórax.

O envelhecimento também traz mudanças anatômicas na caixa torácica, brônquios e vasos pulmonares, que têm conseqüências adversas para a função pulmonar (SHEPHARD, 1997). 


\subsubsection{Caixa torácica}

Uma deformidade no formato da caixa torácica freqüentemente se desenvolve com a idade. Há um aumento na profundidade do tórax que reflete em uma perda ou uma alteração nas propriedades das fibras elásticas no pulmão (D'ERRICO, SCARANI, COLOSIMO, SPINA, GRIGONI \& MANCINI, 1989). As alterações no formato do tórax na idade avançada adversamente afetam as relações tensão/compressão para muitos dos músculos respiratórios (CRAPO, 1993).

\subsection{2 Árvore brônquica}

O envelhecimento pode aumentar o número e/ou tamanho das glândulas na mucosa bronquial, embora seja dificil delimitar uma linha entre as mudanças normais e efeitos que deveriam ser atribuídos à bronquite crônica. Há também um decréscimo progressivo na função ciliar junto a um risco crescente de aspiração de comida (devido a alterações nos reflexos de engolir ) e tosse (TOCKMAN, 1994); e às vezes uma diminuição das respostas imunológicas (ABBAS, LICHTMAN \& POBER, 1995). Estas mudanças deixam o idoso mais vulnerável às infecções bacteriológicas e viróticas (GOODWIN, SEARLES \& TUNG, 1982; ROGHMANN, 1987).

O envelhecimento não necessariamente aumenta as dimensões intrínsecas das vias respiratórias, embora haja geralmente algum aumento do espaço morto anatômico.

Uma progressiva perda de suporte cartilaginoso também deixa as passagens de ar mais vulneráveis ao colapso durante uma expiração forçada (SHEPHARD, 1997). 


\subsubsection{Tecido pulmonar}

O processo de envelhecimento aumenta a taxa volume/peso do pulmão em qualquer pressão de inflação dada (ANDREOTTI, BUSSOTTI, CAMMELLI, AIELLO \& SAMPOGNARO, 1983). O pulmão pode revelar pouca mudança no tecido elástico, mas a elasticidade implica mudança nas propriedades e na locação de tecidos de suporte (DAVIES, 1991). Há uma diminuição no número e espessura das fibras elásticas alveolares. As vias aéreas se tornam estreitas, embora o diâmetro dos dutos alveolares terminais sejam aumentados (D'ERRICO et al., 1989).

O mesmo autor cita que a estrutura fina do pulmão do idoso diminui nas estruturas de suporte. A espessura total da membrana alveolar é diminuída. Ao mesmo tempo, o tamanho alveolar é aumentado e há um aumento no número e no tamanho das aberturas dos poros que conectam alvéolos adjacentes (REISER, HENNESY \& LAST, 1987). A destruição de alvéolos e capilares pulmonares fazem a área funcional do pulmão diminuir cerca de $70 \mathrm{~cm}^{2}$, em 20 anos, para 50 a $60 \mathrm{~cm}^{2}$ em 80 anos (THURLBECK, 1991).

Forças elásticas são reduzidas com o envelhecimento (REISER et al., 1987; THURLBECK, 1991). Células alveolares do tipo II mostram alguma diminuição no número de corpos laminar (SHIMURA, BOATMAN \& MARTIN, 1986), mas a taxa de incorporação de ácido palmético na lecitina é imutável (DEMPSEY \& SEALS, 1995). O total do conteúdo de colágeno e elastina do pulmão também são imutáveis, como são o número e o tamanho das fibras elásticas (THURLBECK, 1991). Por exclusão, a elasticidade diminuída parece atribuível às mudanças moleculares de colágeno (REISER et al., 1987). 


\subsubsection{Vasos pulmonares}

De acordo com DAVIDSON \& FEE (1990), o envelhecimento das artérias pulmonares é marcado pelas alterações na estrutura das paredes do vaso, mais que na circulação sistêmica. Não obstante, as pressões pulmonares são baixas em jovens, assim a magnitude dos aumentos de pressão com a idade é geralmente menor do que na circulação sistêmica.

\subsection{Complacência}

A inclinação da curva de pressão-volume, ou a alteração de volume por unidade de alteração de pressão, é conhecida como complacência. Na faixa normal (pressão de expansão de cerca de -2 a $-10 \mathrm{~cm}$ d'água) o pulmão é notavelmente distensível ou muito complacente. Entretanto, o processo de envelhecimento é marcado por um aumento de rigidez da parede torácica e uma perda de elasticidade do tecido pulmonar, tornando o pulmão mais rígido e a sua complacência é menor (SHEPHARD, 1997). A complacência do pulmão é aumentada pela idade e também por enfisema. As alterações no recuo elástico, que ocorrem no pulmão com a idade e no enfisema, presumivelmente são causadas por alterações no tecido elástico (WEINECK, 1991).

\subsubsection{Complacência da caixa torácica}

Aos 60 anos a resistência elástica do tórax é o dobro do jovem. É provável que a resistência viscosa da parede torácica também aumenea com a 
idade, embora sejam necessárias estatísticas mais precisas. Em conseqüência, pessoas idosas fazem aumentar o uso de diafragma, particularmente quando o pulmão esvazia para menos do que a capacidade residual funcional (TERAMOTO, FUKUCHI, NAGASE, MATSUSE \& ORIMO, 1995).

Aos 80 anos, mudanças da circunferência do tórax reduz para cerca de 1/4 do volume residual e para uma mesma fração no exercício ventilatório (SHEPHARD, 1997).

\subsubsection{Complacência pulmonar}

O tecido elástico é perdido progressivamente dos tecidos do tórax envelhecido. Em conseqüência, a complacência pulmonar aumenta (COTES, 1993; MURRAY, 1981). A complacência maior do pulmão leva a um aumento de volume residual, com a diminuição no volume de reserva respiratória (a diferença entre a capacidade residual funcional e o volume residual).

A doença crônica do tórax e a perda do tecido elástico pulmonar deveriam ser reconsideradas como efeitos intrínsecos do envelhecimento. Uma fração substancial da perda funcional é principalmente a doença respiratória, comumente devido ao fumo e exposição ao ar poluído (ADAIR, 1994; RODE \& SHEPHARD,1996). Contudo, há evidências de que nos não fumantes ativos fisicamente e saudáveis, que tenham sido expostos a somente pequenas concentrações de ar poluentes, a perda da função pulmonar é muito menor do que de indivíduos com uma história de vida menos favorável (SHEPHARD, 1997). 


\subsection{Capacidades e volumes pulmonares}

\subsubsection{Capacidades pulmonares}

As capacidades pulmonares são virtuais, isto é, não são medidas, e sim estimadas por meio de valores dos volumes. Derivadas desses volumes ou fundamentadas na combinação deles existem três capacidades pulmonares: a capacidade inspiratória $(\mathrm{CI})$, que é o volume máximo que pode ser inspirado após uma expiração normal. É composta pela soma do volume corrente (VC) com o volume de reserva inspiratória (VRI). A capacidade residual funcional (CRF), que é o volume de ar remanescente nos pulmões após uma expiração normal composta pela soma do VRE com o VR. Esta capacidade também não pode ser obtida por meio de uma espirometria simples. E a capacidade vital $(\mathrm{CV})$, que é o volume máximo de ar que pode ser expirado após uma inspiração máxima e pode ser entendida como a soma dos quatros volumes (VRI, VRE, VC e VR), (COSTA, 1999).

\subsubsection{Volumes pulmonares}

Cada volume pulmonar depende da idade, sexo, condição de trabalho, assim como do tamanho e do peso do corpo. WEINECK (1991) afirma que, nas mulheres, os volumes pulmonares são aproximadamente $10 \%$ menores que nos homens com igual idade e tamanho. Com o aumento da idade, os volumes pulmonares diminuem; com o aumento da condição fisica eles aumentam. 
A capacidade vital equivale a 3,5 litros em média nas mulheres e a 4, 5 litros nos homens. É a medida de funcionamento pulmonar preferida nas investigações da medicina esportiva. A capacidade vital diminui com o passar dos anos atingindo, aos 60 anos apenas, cerca da metade da capacidade da juventude. Como causa encontramos o enrigecimento da caixa torácica e a diminuição da elasticidade pulmonar.

De acordo com a respiração diferenciamos o volume de inspiração respiratória (VIR), o volume de reserva inspiratória (VRI), o volume de reserva expiratória (VRE), o volume residual (VR), a capacidade vital (CV) e a capacidade total (CT).

A respiração normal ocorre de forma rítmica automática, mas pode também ter um controle voluntário. Em cada respiração absorve-se por volta de $300 \mathrm{ml} \mathrm{de} \mathrm{ar.} \mathrm{Porém,} \mathrm{o} \mathrm{pulmão} \mathrm{tem} \mathrm{a} \mathrm{capacidade} \mathrm{para} \mathrm{muito} \mathrm{mais,} \mathrm{pois} \mathrm{a}$ capacidade pulmonar de um adulto é de cerca de 4 litros. Na respiração cotidiana movimenta-se apenas $10 \%$ do que um pulmão comporta. Assim, o corpo e a mente funcionam com uma quantidade de combustível bem menor do que necessitam e jamais poderão expressar plenamente os potenciais para se viver uma vida realmente saudável se não aumentar a absorção de $\mathrm{O}_{2}$.

Durante a respiração calma o consumo de $\mathrm{O}_{2}$ dos músculos respiratórios é cerca de $1 \mathrm{ml} /$ minuto/litro de ventilação. As necessidades totais de $\mathrm{O}_{2}$ da respiração são acima de $5-10 \mathrm{ml} /$ minuto. $\mathrm{Na}$ hiperventilação as necessidades de $\mathrm{O}_{2}$ podem subir para $3 \mathrm{ml} /$ minuto/litro de ventilação; num débito ventilatório de $75 \mathrm{l} /$ minuto, as necessidades de $\mathrm{O}_{2}$ unicamente para a respiração podem ser de $200 \mathrm{ml} /$ minuto num indivíduo saudável.

Em relação ao consumo máximo de oxigênio $\left(\mathrm{VO}_{2}\right.$ máx. $)$, o declínio máximo relacionado à idade é de $0,4-0,5 \mathrm{ml} / \mathrm{kg} / \mathrm{min} / \mathrm{ano}$, embora sempre devam 
ser consideradas a atividade física e a porcentagem de gordura corporal quando se avalia a diminuição do $\mathrm{VO}_{2}$ máx. com a idade.

O trabalho executado em inflar e desinflar o pulmão pode ser medido pelo produto do volume respiratório e das variações da pressão intra-pleural.

$\mathrm{Na}$ atividade motora, com o aumento do volume minuto respiratório, os músculos auxiliares da respiração passam a apoiar o trabalho respiratório que aumenta durante a atividade. A respiração executa todo seu trabalho através de uma correta adaptação às necessidades orgânicas. As alterações funcionais e até morfológicas, que ocorrem com a atividade motora regular, levam à melhor regulação e economia respiratória (WEINECK, 1991).

\subsubsection{Volumes pulmonares estáticos}

Assim que um indivíduo envelhece ocorre uma diminuição na capacidade vital e no volume residual, determinando uma mudança na capacidade total do pulmão (BURROWS, LEBOWITZ, CAMILLI \& KNUDSON, 1986; COTES, 1993). Na capacidade residual funcional também ocorre uma pequena mudança (COTES, 1993; MURRAY, 1981).

\subsubsection{Capacidade vital}

Muitas das equações usadas para a predição dos volumes pulmonares têm assumido uma perda linear da função no envelhecimento. Na vida adulta há uma relativa perda da função com uma aceleração decrescente de volumes pulmonares nos anos finais de vida (COTES, 1993).

Os estudos de ANDERSON, BROWN, HALL \& SHEPHARD (1968) demonstraram que embora a fumaça tenha influenciado a perda 
significativa da capacidade vital, o efeito desta variável desapareceria se os sujeitos com uma história de doença respiratória crônica fosse excluída da análise. Seus dados são compatíveis com a visão de que embora a fumaça tenha um efeito adverso cumulativo sobre o tecido elástico do pulmão, muito deste impacto é concentrado em um segmento geneticamente vulnerável da população e são, portanto, particularmente vulneráveis à doença crônica do tórax. Quando os indivíduos com a doença crônica foram excluídos da análise, ANDERSON et al. (1968) descobriram que a perda da capacidade vital menor. Pelo menos metade da diferença de gênero/sexo na taxa de envelhecimento poderia ser explicada pela estatura mais baixa das mulheres. A diferença residual pode ter surgido de um efeito da fumaça naqueles que não possuíam doença crônica.

\subsubsection{Volume residual}

$\mathrm{O}$ aumento do volume residual referente à idade reflete em uma expansão do espaço alveolar. A pressão de oxigênio alveolar de um idoso se desenvolve mais lentamente no início do exercício, diminuindo potencialmente sobre o curso do tempo do consumo de oxigênio transitório. A importância maior relaciona-se às conseqüências funcionais indiretas com o volume torácico aumentado: um decréscimo na eficiência mecânica dos músculos torácicos, uma redução da capacidade vital, e uma tendência de dispnéia durante o exercício.

Um aumento de volume residual tem somente um impacto direto sobre a mudança do estado gasoso de um indivíduo com idade entre 65 a 75 anos, mesmo durante exercícios vigorosos.

Para a expansão do volume residual que ocorre nos terminais dos dutos alveolares, ao contrário do que na propriedade alveolar, há um aumento em 
séries de espaços mortos; isto retarda a mistura difusional entre o ar inspirado e o gás alveolar (SHEPHARD, 1997).

\subsection{Dinâmicas pulmonares}

A capacidade de desenvolver grandes fluxos de ar durante $o$ exercício, depende de fatores como o da força do músculos torácicos, alguma inibição voluntária de sua contração, e a impedância apresentada pela complacência, resistência das vias aéreas, e colapso das vias aéreas (SHEPHARD, 1997).

\subsubsection{Performance do músculo respiratório}

O desgaste dos músculos acessórios podem reduzir o pico de pressão respiratório, ou seja, limita a porção do esforço dependente de ventilação. Dados empíricos geralmente mostram que o pico de pressão respiratório que uma pessoa pode desenvolver, diminui com a idade, mas há muita variação entre os indivíduos. No relatório de McELVANEY et al.* (1989), apud SHEPHARD (1997), a diferença média entre jovens e indivíduos com idade de 70 anos não foi estatisticamente significativo. Em outro estudo com sujeitos de 69 anos não houve nenhuma patologia pelo pico de pressão inspiratório. Permanece a necessidade de testar o pico de fluxo da capacidade respiratória em idosos sobre um estudo longitudinal (JOHNSON, REDDAN, PEGELOW, SCOW \& DEMPSEY, 1991; JOHNSON, REDDAN, SCOW \& DEMPSEY, 1991).

* G. N. McELVANEY, et al. Cardiac output at rest and during exercise in elderly subjects,

Medicine and Science in Sports and Exercise, v.21, p. 293-8, 1989. 


\subsubsection{Colapso e impedância das vias aéreas}

$\mathrm{O}$ afinamento da parede mucosa nas passagens menores de ar e o decréscimo da complacência torácica tendem a estreitar as pequenas passagens de ar das vias aéreas de um idoso. Isto aumenta a resistência do fluxo aéreo expiratório e inspiratório (JOHNSON et al.,1991b). Bem como o grau de pressão do pulmão para a via aérea extra-torácica para qualquer taxa de fluxo dada. $\mathrm{O}$ colapso da via aérea ocorre se o grau de pressão do alvéolo para o brônquio maior excede substancialmente a força oposta oferecida pelo recuo elástico dos tecidos pulmonares. $\mathrm{O}$ envelhecimento progressivo aumenta a relação que uma pessoa, que pratica exercícios vigorosamente, alcançará a porção de esforçoindependente da curva fluxo/volume expiratória, onde mais esforços expiratórios causam um colapso das vias aéreas sem o aumento do fluxo aéreo (JOHNSON \& DEMPSEY, 1991).

O aumento do volume do pulmão no fluxo expiratório expande as vias aéreas, inibindo a tendência do colapso. No entanto, ocorre um considerável decréscimo na eficiência mecânica dos músculos respiratórios.

A complacência dinâmica global também diminui, uma vez que o sujeito idoso tende a utilizar a parte menos complacente da curva pressão/volume durante a respiração.

\subsubsection{Volumes pulmonares dinâmicos}

As vias aéreas estreitadas e o colapso expiratório das passagens de ar diminuem os índices da função dinâmica pela idade, tais como, a ventilação voluntária máxima, a taxa de pico fluxo expiratório e o volume expiratório forçado em 1 segundo (ANDERSON et al., 1968; COTES, 1993; DEMPSEY \& 
SEALS, 1995). O envelhecimento é comumente ligado à maior perda de volume expiratório forçado em 1 segundo da capacidade vital. O volume expiratório forçado em 1 segundo em um jovem pode ser de $82 \%$ para $86 \%$ e em um indivíduo com 65 anos ou mais, de 75\% a 79\% (SHEPHARD, 1997).

Quando os volumes pulmonares dinâmicos observados em idosos são expressados como porcentagens de valores de um jovem e essas perdas são apresentadas como similares à diminuição do consumo de oxigênio máximo, a margem de reserva ventilatória é pequena.

JOHNSON \& DEMPSEY (1991) notaram que as pessoas de 70 anos alcançavam seus limites de taxa de fluxo respiratório sobre $40 \%$ a $90 \%$ da capacidade vital, e muitos dos indivíduos eram incapazes de aumentar a ventilação suplementar se a concentração de dióxido de carbono inspirado era deliberalmente aumentada enquanto eles estavam em exercício máximo.

\subsection{Trocas gasosas}

O envelhecimento dificulta a troca gasosa através de uma distribuição debilitada de gás inspirado, com uma piora da ventilação alveolar e difusão pulmonar e um aumento gradativo de pressão alveolar-arterial (SHEPHARD, 1997).

\subsubsection{Distribuição gasosa}

Para a idade de 65 anos a obstrução das vias aéreas ocorre em menos de um quarto da capacidade vital (COTES, 1993; TOCKMAN, 1994). Por razão hidrostáticas, a obstrução restringe a ventilação principalmente nas partes dependentes do pulmão. Infelizmente, uma fração maior do fluxo sangüíneo 
pulmonar total é distribuído para a terça parte do pulmão, também por razões hidrostáticas. Portanto, o colapso das vias aéreas provoca uma piora progressiva das combinações entre ventilação e perfusão do pulmão com um aumento no componente alveolar do espaço morto do pulmonar (DEMPSEY \& SEALS, 1995). Em parte, por causa da obstrução das vias aéreas e da complacência pulmonar e resistência do fluxo aéreo, torna menos uniforme conforme a idade aumenta. Porém, observações em relação à distribuição gasosa têm geralmente sido feitas sob condição de repouso e as conclusões não necessariamente se aplicam ao exercício vigoroso (SHEPHARD, 1997).

\subsubsection{Ventilação alveolar}

O envelhecimento geralmente leva a algum aumento no espaço morto anatômico dos condutores das vias aéreas. COTES (1993) tem estimado o aumento no volume bronquial em $10 \mathrm{ml} /$ década. Porém, esta mudança é relativamente pequena quando comparada ao crescimento do espaço morto fisiológico que resulta a partir do fechamento das vias aéreas, expansão dos dutos alveolares terminais, um lento equilíbrio de gás entre as vias aéreas e uma pobre combinação de ventilação com perfusão.

A perda de capilosidades pulmonares relacionada ao envelhecimento deixam um grande número de espaços alveolares insuflados, aumentando o espaço morto fisiológico. Um pequeno aumento da pressão arterial pulmonar melhora a perfusão das regiões de pico do pulmão, mas a hipertensão pulmonar restringe o fluxo de sangue pulmonar de pico, piorando a combinação entre ventilação alveolar e perfusão. Em vista desses vários problemas, uma piora substancial da combinação normal da ventilação e perfusão pode ser antecipada em indivíduos idosos (DAVIES, 1991). 
Na prática, as taxas de repouso da ventilação/perfusão para idosos saudáveis são surpreendentemente normais. JOHNSON \& DEMPSEY (1991) sugeriram que sob condições de repouso a taxa de volume tempo/espaço morto total foi de $15 \%$ a $20 \%$ maior em sujeitos idosos, mas que mesmo este fato diminui progressivamente durante o exercício. DERKS ${ }^{*}, 1980$ apud SHEPHARD (1997) relatou que em exercícios vigorosos a ventilação alveolar foi cerca de $70 \%$ da ventilação externa, quando comparado com $75 \%$ a $80 \%$ em um jovem.

\subsubsection{Difusão pulmonar}

A difusão pulmonar (Dp) depende da capacidade de difusão da membrana pulmonar $(\mathrm{Dm})$, o produto do volume de sangue capilar pulmonar $(\mathrm{Vc})$ e uma constante reação de hemoglobina $(\mathrm{O})$. Os valores de repouso para Dm diminui depois dos 40 anos e há também um decréscimo de Vc porque os capilares pulmonares têm sido destruídos. Expressando Dp em unidades tradicionais a perda anual da capacidade de difusão é cerca de $0,15 \mathrm{ml} /$ minuto por mmHg (HORVATH \& BORGIA, 1984). Como em muitas outras funções do corpo, há então, uma perda cumulativa de cerca de $25 \%$ sobre o intervalo de vida de trabalho.

A mudança corresponde com a diminuição em área funcional do gás permutado na superfície (THURLBECK, 1991), embora uma parte da deteriorização da permuta gasosa seja provavelmente devido à pobre distribuição de gás inspirado, ao contrário do que para uma perda de superficie alveolar. Porque o exercício aumenta a uniformidade da ventilação e perfusão, os sujeitos

* C.M. DERKS. Ventilation/perfusion distribution in young and old volunteers during mild exercise, Bulletin Européan de Physiopathologie Respiratoire, v. 16, p. 145-54, 1980. 
de 65 anos saudáveis e relativamente capazes mostram um pouco da perda da capacidade de difusão máxima. A saturação de oxigênio arterial é geralmente mantida durante o exercício máximo.

\subsubsection{Gradientes de pressão alveolar-arterial}

$\mathrm{Na}$ maioria dos jovens não há quase nenhum gradiente de pressão parcial de oxigênio entre os espaços alveolares e o sangue arterial. Paradoxalmente, o equilíbrio é mais pobre em atletas de resistência. Tais indivíduos às vezes desenvolvem um gradiente de pressão alveolar-arterial significativo durante exercício vigoroso, pois o sangue passa tão rápido através de alguns de seus capilares que não tem tempo de equilibrar com o gás alveolar (DEMPSEY, POWERS \& GLEBHILL, 1990). Deveria ser através disso que a diminuição na camada capilária pulmonar agravaria o problema de equilíbrio incompleto, mas na prática isto é geralmente desligado por uma saída cardíaca de pico menor em indivíduos idosos. Então, o tempo disponível para o equilíbrio não diminui muito com a idade.

JOHNSON \& DEMPSEY(1991) descobriram que o gradiente de pressão parcial de oxigênio alveolar-arterial em repouso de sujeitos de 70 anos era somente de 2 a $5 \mathrm{mmHg}$ maior do que seus valores para jovens. Mesmo durante o exercício máximo, somente quatro dos 19 idosos tinham uma pressão de oxigênio arterial menor de $75 \mathrm{mmHg}$ ou uma saturação de oxigênio arterial menor que $92 \%$.

Assim, como em jovens, os idosos estão sob risco de uma redução na saturação de oxigênio durante exercícios vigorosos (PRÉFAUT, ANSELME, CAILLAUD \& MASSÉ-BIRON, 1994). 


\section{Trabalho respiratório}

A magnitude do trabalho de respiração depende da demanda ventilatória e da eficiência mecânica do pulmão (SHEPHARD, 1997).

\subsubsection{Demandas ventilatórias}

A sensitividade dos centros respiratórios para estímulo, tais como, dióxido de carbono e falta de oxigênio, pode diminuir em $50 \%$ relativo ao de um jovem (DILL, HILLYARD \& MILLER, 1980), mas o volume respiratório minuto em repouso pouco muda com a idade.

Durante o exercício sub-máximo, ao contrário, a ventilação por umidade do trabalho externo parece aumentar de $3 \%$ a $5 \%$ por ano (DAVIES, 1991). Muitos fatores aumentaram a demanda ventilatória de uma pessoa idosa. $O$ custo do oxigênio de uma dada atividade é aumentado. Há um acúmulo maior de lactato durante o trabalho sub-máximo, devido ao aumento mais lento de consumo de oxigênio no início do exercício (BABCOCK, PATERSON, CUNNINGHAM \& DICKINSON, 1994). Há também uma contração miocardial mais pobre, músculos esqueléticos mais fracos e uma circulação periférica debilitada. Finalmente, há uma redução na eficiência mecânica do pulmão.

Ao contrário, o volume respiratório minuto observado durante o esforço aeróbio máximo é menor do que em uma pessoa mais nova, talvez porque as taxas de fluxo expiratório limite foram alcançadas (DEMPSEY \& SEALS, 1995). 


\subsubsection{Custo de oxigênio de trabalho externo}

O custo do oxigênio da contração do músculo esquelético durante a maioria das formas de trabalho externo é aumentado pela rigidez da articulação, coordenação motora pobre, aumento do trabalho corporal e/ou uma falta de familiaridade recente com a atividade em questão. Isto diminui a eficiência mecânica. Por exemplo, a eficiência mecânica do círculo ergômetro diminui de $23 \%$ em um jovem para $21,5 \%$ em uma pessoa de 65 anos. O custo do oxigênio total da atividade física é aumentado mais adiante em um idoso por causa do aumentó no trabalho respiratório. O aumento de pressão sistêmico do sangue também causa algum aumento no consumo de oxigênio do coração relativo aos gastos em um indivíduo jovem (SHEPHARD, 1997).

\subsubsection{Eficiência mecânica do pulmão}

A redução de fatores de eficiência de ventilação em uma pessoa idosa inclui: deformidade da costela por um problema postural e deformidade de formato, adoção de um volume temporal menor com uma taxa respiratória acelerada, um aumento na resistência das vias aéreas e resistência do tecido, uma mudança de ventilação para um alto volume do diafragma de volume/ pressão e um colapso expiratório das vias aéreas (JOHNSON\& DEMPSEY, 1991). Ventilação é também aumentada para compensar o aumento do espaço morto anatômico e fisiológico. 


\subsubsection{Custo de oxigênio do trabalho respiratório}

$\mathrm{O}$ aumento na rigidez da caixa torácica é por uma complacência maior nos tecidos do pulmão, assim que ocorre uma mudança no trabalho elástico realizado durante o ciclo de respiração. Porém, o trabalho de ventilação é aumentado no idoso devido ao estreitamento e/ou colapso das grandes vias aéreas. JOHNSON \& DEMPSEY (1991) citam que os músculos do tórax consomem somente $6 \%$ do consumo de oxigênio máximo em um jovem e de $13 \%$ do custo de oxigênio máximo em um indivíduo de 70 anos.

A maioria dos idosos são propensos a algum tipo de enfisema, o que aumenta o custo de oxigênio do trabalho respiratório.

\subsection{Função pulmonar}

A função pulmonar se divide em função ventilatória (deslocamento da massa de ar desde a atmosfera até os bronquíolos) e função respiratória (permuta de $\mathrm{O}_{2}$ e $\mathrm{CO}_{2}$ entre $\mathrm{o}$ ar alveolar e o sangue capilar). A função respiratória depende da massa de ar ventilado, da distribuição uniforme do ar inalado, da difusão dos gases através da membrana alvéolo-capilar e da distribuição uniforme do sangue capilar nos pulmões. Assim, o pulmão deve promover uma ventilação adequada e uma efetiva troca de gases, ou seja, garantir as funções ventilatória e respiratória (RATTO* apud TEIXEIRA, 1993a).

Os estudos da função pulmonar são essenciais para o diagnóstico e avaliação das anormalidades, pois os sintomas descritos pelos sujeitos e os

* O. R. RATTO, et al. Estudo comparativo de diversos parâmetros para a avaliação da obstrução brônquica, Jornal de pneumologia, v.5, n. 1, p.5-10, 1975. 
achados do exame físico não estão freqüentemente relacionados com a variabilidade e a gravidade da obstrução do fluxo aéreo. Anormalidades da função pulmonar são classificadas como insuficiências restritivas, obstrutivas ou mistas (restritivas/obstrutivas). Identificar o tipo de insuficiência não implica identificar a alteração anatômica ou patológica. Contudo, os processos patológicos específicos são muitas vezes associados com cada tipo. As insuficiências restritivas são diagnosticadas quando a anormalidade primária é uma redução no volume pulmonar sem aparente obstrução do fluxo aéreo. São muitas vezes associadas à limitação dos movimentos da parede torácica. Insuficiências obstrutivas resultam da diminuição do fluxo aéreo através da traquéia e brônquios, principais dos sacos alveolares. Secreções brônquicas, broncoespasmos, perda da estrutura de suporte ou edema da parede bronquial levam a um comprometimento obstrutivo.

\subsection{Os efeitos da atividade motora na função pulmonar de idosos}

Cada vez mais estudos vêm evidenciando a necessidade do envolvimento em atividades de movimento ou atividade motora como recurso importante para minimizar a degeneração provocada pelo envelhecimento, possibilitando ao idoso manter uma qualidade de vida ativa.

Segundo OKUMA (1998), estudos em gerontologia têm demonstrado que a atividade física, junto com a hereditariedade, alimentação adequada e hábitos de vida apropriados, podem melhorar em muito a qualidade de vida dos idosos. A atividade física deve ser realizada pelo menos três vezes por semana, durante 20 a 40 minutos em cada sessão, orientada e supervisionada (MCARDLE, KATCH \& KACTH,1992). 
As primeiras manifestações relacionadas com a influência das atividades motoras no processo de envelhecimento aparecem com a publicação do artigo de 1968 de RIBEIRO, e os primeiros resultados de pesquisas começaram a ser publicados na década de 70 . Um bom exemplo é a primeira dissertação de mestrado apresentada no Brasil tratando da temática da atividade física para idosos (FARIA JUNIOR \& RIBEIRO, 1995).

De acordo com WEINECK (1991), o único método até hoje cientificamente seguro de manter o homem que está envelhecendo biologicamente, mais jovem do que corresponde à sua idade cronológica é o treinamento corporal. Os efeitos de um programa de atividade motora podem oferecer uma redução equivalente a 20 anos na idade biológica do indivíduo, reduzir o risco de aparecimento de doenças como a aterosclerose, o diabetes, a osteoporose e outras doenças crônicas (SHEPHARD, 1994).

Um estudo, que teve como objetivo evidenciar os beneficios da prática de atividades fisicas sistemáticas em um grupo de idosos, foi realizado por ANTONIAZZI (1994) no programa de atendimento a terceira idade da UFSM. A pesquisa teve um desenho quase experimental e foram utilizados para o estudo dois grupos, submetidos a um pré e pós-teste. Foi utilizada uma amostra selecionada intencionalmente através da participação voluntária de indivíduos integrantes e não integrantes do programa, com idade superior a 60 anos, de ambos os sexos. O grupo experimental foi composto por vinte e um sujeitos e sete para o grupo controle. A coleta de dados seguiu o protocolo padrão de avaliação funcional do Setor de Fisiologia do Exercício do LAPEM/CEFD/UFSM, e utilizados a estatística descritiva e o teste " $t$ " de Student. Foi realizado também um questionário para avaliar a qualidade de vida através das atividades dos sujeitos da amostra. O tratamento teve a duração de seis meses. Concluiu-se, com à relação à condição física, que o grupo 
experimental aumentou o seu consumo de oxigênio após o periodo de seis meses, em ambos os sexos, enquanto que o grupo masculino controle reduziu o seu consumo máximo de oxigênio e para o feminino não houve modificação. Através dos resultados obtidos pode-se concluir pelo questionário que a atividade física regular agiu de forma extremamente positiva, contribuindo para uma melhor qualidade de vida em indivíduos acima de 60 anos.

Vários autores, entre eles, PESCATELLO \& DI PIETRO (1993), SPIRDUSO \& ECKERT (1989) e SHEPHARD (1994), são unânimes em reconhecer alguns benefícios que a atividade física pode proporcionar aos idosos: melhoria da qualidade de vida, como o aumento da capacidade do coração e dos pulmões de suprir oxigênio; o aumento do metabolismo aeróbio; o fortalecimento das estruturas esqueléticas, músculo e articulações ósseas; a diminuição e prevenção de doenças como a arteriosclerose, o diabetes, a osteoporose; e o aumento da aptidão física com melhora da força, flexibilidade, coordenação e equilíbrio, prevenindo assim a incapacidade e a dependência nos últimos anos de vida.

MATSUDO (1997b) resume os principais efeitos metabólicos da atividade motora no idoso, tais como, como o aumento do volume sistólico, do $\mathrm{VO}_{2}$ máx. 10-30\%, da ventilação pulmonar, melhora do perfil lipídico, a diminuição da freqüência cardíaca em repouso e no trabalho submáximo e diminuição da pressão arterial.

Em relação ao sistema respiratório, TEIXEIRA, CABRAL \& FERNANDES (1999) citam que a atividade motora representa um estímulo importante para o transporte de oxigênio, pois requer uma interação dos mesmos para suportar o aumento da demanda metabólica e de trocas gasosas. Muitas funções do sistema respiratório alteram-se em resposta ao exercício. Os estudos de TEIXEIRA (1993b) têm verificado modificações na função pulmonar 
decorrentes da atividade motora. Estudos que verificaram a relação entre programas de atividade motora e disfunção respiratória apontam e aceitam que as atividades motoras são consideradas benéficas para idosos com disfunções pulmonares. Como os estudos de TEIXEIRA (1996), verificaram os efeitos positivos sobre o volume pulmonar e sobre a condutância nas pequenas vias aéreas.

O I Consenso Brasileiro de Educação em Asma (EDITORIAL,1996) e alguns autores como TEIXEIRA (1999), PENNOCK (1983) sugerem o exercício físico como parte da terapêutica não farmacológica para o indivíduo com disfunção respiratória. Dentre os benefícios proporcionados pela prática da atividade motora destaca-se o alto grau de independência, melhorando as condições de vida.

Neste sentido os idosos têm sido encorajados a se inserir em programas onde são desenvolvidos atividades motoras.

De acordo com ASTRAND (1960), as milhares de células, tecidos e órgãos do nosso corpo, em qualquer idade, quando submetidos a estímulos, sofrem um processo de adaptação. Isso significa que um programa de atividade motora regular pode funcionar como um componente essencial para a manutenção e/ou melhora de algumas funções do organismo. Diversos estudos sugerem que o condicionamento físico, melhorado pelo treinamento aeróbio, pode melhorar e/ou aumentar a capacidade vital inicial e a eficiência cardiorespiratória (BRINER JÚNIOR \& SIIEFFER,1992; HORAN, SHEFFER \& BRINER JÚNIOR,1992; KURABAYASHI, KUBOTA, MACHIDA, TAMURA, TAKE \& SHIRAKURA, 1997; KWAN-GETT, LOZANO, MULLIN \& MARCUSE,1997).

GANNON (1999) no estudo sobre a correlação da força do músculo abdominal e funções pulmonares em idosos, analisou as relações entre as 
variáveis da função pulmonar e força do músculo abdominal em 33 idosos voluntários na faixa etária de 50 a 84 anos de idade.

Foram realizadas duas avaliações. A primeira incluindo avaliações antropométricas, medidas de pico de fluxo expiratório, as variáveis da função pulmonar através da espirometria e teste abdominal de 25 repetições/minuto até o individuo cansar. A segunda avaliação analisou qual pico de força isométrica do músculo abdominal.

Foram feitas medidas de força usando uma plataforma de força modificada. As relações entre as variáveis medidas foram avaliadas por uma série de correlações bivariadas.

As variáveis da função pulmonar analisadas foram a capacidade vital forçada $(\mathrm{CVF})(\mathrm{r}=0,721)$, fluxo expiratório forçado entre $25 \%$ e $75 \%$ (FEF $25 \%-75 \%)$ da capacidade vital forçada $(r=0,676)$, fluxo expiratório forçado a $50 \%$ (FEF 50\%) da capacidade vital forçada $(r=0,706)$, volume de fluxo expiratório forçado em um segundo $\left(\mathrm{FEF}_{1}\right)(\mathrm{r}=0,765)$ e taxa de pico de fluxo registrado pelo monitor peak-flow $(r=0,806)$.

Este estudo revelou várias relações significativas entre força de músculo abdominal e a função pulmonar em uma população de idosos.

SHARRATT \& BRAWLEY (1988) analisaram o impacto fisiológico e psicológico de exercício moderado em adultos mais velhos, sedentários, que participaram de um programa sistemático de exercício.

Foram testados, através de exercício graduado e medidas respiratórias freqüentes, com provas de espirometria antes e após o programa de treinamento. A amostra consistiu de vinte idosos, aparentemente saudáveis, (10 homens e 10 mulheres) com uma média de idade de 70 anos.

Foi aplicado um questionário psicológico baseado em um modelo de comportamento planejado e avaliação da aptidão. Os idosos demonstraram 
melhoria significativa em eficiência cardiovascular e em função pulmonar depois de seis meses de exercício.

Apresentaram atitudes muito positivas para freqüentarem as aulas do início ao término do programa. Eles responderam muito bem ao estímulo para continuarem exercitando-se depois da conclusão do programa, uma vez que antes era negativa a sua participação em aulas regulares.

Os autores sugerem mais investigações com controle de categorias de idade, sexo e diferenças socioeconômicas.

ETNIER, JOHNSTON, DAGENBACH, POLLARD, REJESKI \& BAGA (1999) estudaram as relações entre função pulmonar, aptidão aeróbia e aspectos cognitivos em idoso, com Doença Pulmonar Obstrutiva Crônica (DPOC).

Os indivíduos, com idades de 56 a 80 anos, participaram de um programa de intervenção e foram analisados o nível de depressão, de educação, aptidão aeróbia, nível de saturação de oxigênio do sangue, função pulmonar e provas.

Conclui-se que em uma amostra de idosos com DPOC o envelhecimento, a aptidão aeróbia e a função pulmonar são preditores de desempenho cognitivo em várias tarefas. Em particular, idade e aptidão aeróbia são preditores de velocidade no processo cognitivo variável que pode estar dependente de desempenho em uma maioria de tarefas cognitivas.

BOEZEN, RIJCKEN, SCHOUTEN \& POSTMA (1998) realizaram estudos sobre a falta de ar em indivíduos idosos relacionada com a função pulmonar e reversibilidade de obstrução das vias aéreas em que a percepção de falta de ar é um fator relacionado à doença respiratória, doença cardíaca e sobrepeso. 
Foi estudada a relação da falta de ar associada às doenças respiratórias, doença cardíaca e sobrepeso, bem como sua associação com a função pulmonar, a reversibilidade de obstrução das vias aéreas e o pico de fluxo expiratório (PEF).

Foram coletados dados referentes à falta de ar (Escala de Borg), função pulmonar, reversibilidade, variabilidade do PEF, sintomas respiratórios, doença cardíaca e sobrepeso em 210 idosos (acima de 55 anos de idade) que participaram de um teste de aptidão física.

Indivíduos que com falta de respiração na escala de Borg apresentaram a marca $>0(n=50,24 \%)$, eram três a cinco vezes mais prováveis de terem uma função pulmonar reduzida e grande reversibilidade. Escala de Borg com pontuação zero, independente da presença de sintomas respiratórios, doença cardíaca ou sobrepeso, embora estes três fatores fossem todos associados com função pulmonar reduzida, uma grande reversibilidade e pico de fluxo expiratório.

É freqüente a presença de falta de ar em indivíduos idosos e a escala de Borg parece ser uma importante medida clínica, pois é um importante preditor independente de deterioração de função pulmonar no idoso.

Se algumas das perdas fisiológicas com a idade podem ser explicadas através de processos associados, pode-se sugerir que intervenções adequadamente planejadas, tais como, os programas de atividades motoras, podem prevenir algumas das perdas e podem beneficiar o sistema respiratório do idoso. 


\section{METODOLOGIA}

\subsection{Caracterização da pesquisa}

O estudo realizou-se através da análise inferencial e descritiva, estudando um grupo específico de indivíduos. Utilizando-se da pesquisa de campo que, segundo LAKATOS \& MARCONI (1991), tem por objetivo a coleta sistemática de dados sobre programas ou amostra de populações. Busca o delineamento ou análise das características de fatos ou fenômenos e a avaliação de programas. Durante o estudo todos os participantes foram testados em duas ocasiões: início do programa e após 12 semanas de treinamento. Uma avaliação inicial e final foi realizada através da espirometria e um período de avaliação periódica pelo monitor de pico de fluxo expiratório.

\subsection{Amostra}

Participaram deste estudo 33 voluntários selecionados, de ambos os sexos, fisicamente independentes, com idade cronológica média de 76,4 anos. Os participantes eram originários da Divisão de Seleção e Cadastro do Serviço de Assistência Social do Hospital das Clínicas da cidade de Londrina, no estado do Paraná, através do Programa Interdisciplinar de Assistência à Saúde do Idoso (PIASI).

A amostra foi dividida em grupo comparativo (GC) e grupo experimental (GE). O GC foi formado por 12 voluntários que não tinham disponibilidade de participação semanal. O GE foi formado por 21 voluntários que participaram do programa de atividades motoras. 


\section{3}

\section{Procedimentos}

A primeira etapa do presente estudo se deteve em diagnosticar as características da função pulmonar de idosos participantes do PIASI, que foram encaminhados a um programa de atividades motoras com o objetivo de verificar os efeitos desse programa sobre a função pulmonar.

Este estudo passou pela aprovação do Comitê de Ética em Pesquisa do Hospital Universitário da Universidade Estadual de Londrina - Paraná (APÊNDICE 1).

Os participantes assinaram um termo de consentimento (APÊNDICE 2) e foram preenchidos prontuários contendo a história clínica e hábitos de vida de cada individuo do programa (ANEXO I) para saber se apresentavam algum tipo de sintoma clínico ou patologia que pudesse interferir ou colocá-los em risco durante o programa.

Foi solicitado aos sujeitos avaliados a participação em atividades motoras somente no projeto durante o período de estudo.

Foram realizadas as provas de função pulmonar (pré), através da espirometria e determinação do pico de fluxo expiratório pelo do monitor de pico de fluxo expiratório (Wright Peak Flow Meter).

As espirometrias foram realizadas em ambos os grupos- comparativo e experimental, na pré e pós intervenção do programa de atividades motoras e o acompanhamento semanal do pico de fluxo expiratório somente no grupo experimental. O grupo experimental participou do programa de atividades motoras com 12 semanas de intervenção, uma vez por semana, realizadas às $6^{\mathrm{a}}$ feiras, com sessões de 60 minutos cada aula, divididos em quatro sessões para atividades de caminhadas, quatro sessões de hidroginástica e quatro sessões de exercícios aeróbios, precedidos de exercícios de alongamento e de relaxamento 
após o término das aulas. $\mathrm{O}$ atendimento da Educação Física era intercalado com as outras atividades quinzenais, específicas das áreas integrantes do projeto, em que os idosos eram atendidos individualmente nas sessões de psicologia, enfermagem, fisioterapia e medicina. Além de atendimentos grupais nas sessões de serviço social, artes e nutrição.

Após 12 semanas de prática regular de atividades motoras, foram realizadas as provas de função pulmonar (pós), dos grupos comparativo e experimental.

Para todos os grupos foram analisadas quatro variáveis da função pulmonar $\mathrm{CVF}, \mathrm{FEV}_{1}, \mathrm{PEF}$ e $\mathrm{FEF}_{25 \%}$ - 75\%, que estão entre as variáveis mais estudadas pela facilidade em indicarem as variações e alterações ventilatórias e através das quais se pode verificar a eficiência respiratória. No entanto, para eliminar os efeitos da influência do peso, estatura e idade calculou-se inicialmente o afastamento relativo do padrão (ARP), para cada variável, pelas tabelas de POLGAR \& PROMADHAT (1971) que fornecem uma medida padrão, dado por:

$$
\text { Afastamento relativo padrão }=\left(\frac{\text { medida padrão }- \text { medida de teste }}{\text { medida padrão }}\right)-100
$$

Após ter realizado esse procedimento, tanto na pré como na pós intervenção, foi conduzido o cálculo da porcentagem de alteração entre o afastamento relativo do padrão do pré e pós no grupo comparativo e experimental, o qual é dado por:

$\%$ de alteração $=\underline{\mathrm{ARP}}($ Pós $)-\mathrm{ARP}($ Pré $)$ 


\subsubsection{Local de realização dos testes}

Todos os testes foram realizados nas instalações do CENESP- Centro de Excelência em Pesquisa do Centro de Educação Física da Universidade Estadual de Londrina-Paraná.

\subsubsection{O programa PIASI}

O programa PIASI (Programa Interdisciplinar de Assistência à Saúde do Idoso) constitui-se num projeto de extensão à comunidade, desenvolvido no Hospital das Clínicas da Universidade Estadual de Londrina- Paraná. O programa assiste aos idosos de maneira interdisciplinar, com a efetiva integração de várias áreas de interesse gerontológico (Medicina, Enfermagem, Psicologia, Fisioterapia, Educação Física, Nutrição, Artes e Serviço Social). A equipe de profissionais tem como preocupação os aspectos biológicos, sociais e culturais do envelhecimento, estruturando um serviço de atendimento a idosos e na sensibilização da comunidade para esta população.

O programa tem como objetivos: a realização de estudos específicos relativos ao idoso; desenvolver estratégias e metas de prevenção/educação que permitam a identificação de doenças e problemas psicossociais; e sobretudo, novas alternativas terapêuticas para minimizar o impacto negativo da velhice no bem estar do indivíduo, da sociedade e dos gastos com saúde. Busca o aprimoramento em diferentes áreas profissionais e na formação de recursos humanos qualificados para atender à demanda desse grupo populacional. Está em consonância com a lei 8.842 de 04 de janeiro de 1994 que trata da Política Nacional do Idoso que determina a inclusão da Geriatria e Gerontologia como disciplinas curriculares nos cursos superiores. Oportuniza aos acadêmicos de 
graduação envolvidos no projeto: a vivência de questões teórico-práticas associadas à Geriatria e Gerontologia e ao trabalho interdisciplinar; e possibilita o atendimento integral ao idoso, viabilizando, através das ações interdisciplinares, o desenvolvimento à compreensão e reflexão crítica das questões pertinentes ao seu envelhecimento num contexto bio-psico-social.

As atividades são desenvolvidas no ambulatório do Hospital das Clínicas, Laboratório de Artes, Centro de Educação Física, Ambulatório de Fisioterapia e Clínica Médica do Hospital Universitário, onde são atendidos idosos acima de 60 anos da comunidade Londrinense e região, por um período de um ano, com encontros quinzenais para o atendimento no ambulatório e semanais na Educação Física, para a intervenção do programa de atividades motoras de 60 minutos cada sessão. Nos encontros quinzenais os idosos são atendidos no ambulatório do Hospital das Clínicas no período da manhã pelas áreas de Serviço Social, Nutrição, Enfermagem e Psicologia, permanecendo das $8: 00$ às 12:00 horas. No período das $13: 30$ às $15: 30$ horas são atendidos no laboratório de Artes. Das 15:30 às 17:00 horas fazem atividades motoras no Centro de Educação Física, tendo a freqüência semanal. $O$ atendimento pela fisioterapia no Hospital Universitário é realizado em dias e horários agendados com cada participante.

A cada ano são selecionados outros idosos para se integrarem ao projeto. A seleção se faz através de critérios médicos, psicológicos e sociais, de acordo com interesses da equipe de profissionais do programa para estudos das características apresentadas pelos indivíduos. São selecionados 24 idosos. Esse número é determinado pelas consultas individuais que a área médica consegue atender no período em que os idosos permanecem no ambulatório.

Existe uma preocupação constante com a integração dos profissionais e estudantes de cada área. Para tanto, são programadas reuniões interdisciplinares 
semanalmente e organizadas oficinas de avaliação e integração da equipe. Investindo na qualificação de profissionais e de discentes de diferentes áreas, o projeto assume papel de integração com os demais serviços de assistência ao idoso da comunidade. Nesse sentido interagem os grupos de estudo em Geriatria e Gerontologia, disciplina especial de Gerontologia, oficinas de reciclagem e equipes das Unidades Básicas de Saúde, sistematizando a produção e aplicação dos conhecimentos na área de forma interdisciplinar. O projeto forma agentes multiplicadores e proporciona aos universitários das diferentes áreas a oportunidade de contato e aprendizado com esta população e sua realidade.

\subsection{Instrumentos}

\subsubsection{Avaliações antropométricas}

Foram efetuadas as medidas de peso corporal em quilogramas e a estatura em centímetros. Para a avaliação do peso corporal foi utilizada uma balança digital, marca Urano Ps 180 , com capacidade para suportar $180 \mathrm{Kg}$ com o fracionamento do peso corporal em $100 \mathrm{~g}$. O indivíduo, com o mínimo de roupa possivel e sem calçado, permaneceu em pé, de costas para o monitor demonstrativo, sobre a plataforma, e no centro desta, ereto, com os braços ao longo do corpo, e com o olhar num ponto fixo a sua frente, permanecendo imóvel para evitar oscilações na medida.

No estadiômetro, com o auxílio do cursor, determinou-se a estatura, medida correspondente à distância entre a região plantar e o vértex, estando o avaliado em apnéia inspiratória e com a cabeça orientada no plano de Frankfurt paralelo ao solo (LOHMAN, ROCHE \& MARTORELL,1992). 
Estes dados, a data de nascimento e o sexo foram transcritos para o computador que calculou os valores individuais esperados e acoplado a um espirômetro, permitiu a realização da espirometria.

Cada equipamento utilizado passou por uma checagem específica, como por exemplo, o espirômetro que foi calibrado inicialmente com cilindro de gás comprimido de acordo com as normas de utilização.

\subsubsection{Medição da função pulmonar}

Uma aplicação prática importante da fisiologia respiratória é a análise da função pulmonar. Estas provas são úteis em uma variedade de contextos. Auxiliam no diagnóstico, seguimento, tratamento e prescrição de atividades para indivíduos com doenças pulmonares ou cardíacas. Além disso, elas podem ser valiosas para se decidir se um sujeito é suficientemente apto para o exercício. Outra utilização é na avaliação de incapacidade para finalidades de indenização do trabalho. O papel dos testes de função pulmonar deve ser mantido em perspectiva. Eles raramente são um fator-chave para se fazer um diagnóstico definitivo em um indivíduo com doença pulmonar. Embora os testes muitas vezes sejam valiosos para se acompanhar a progressão de um sujeito com doença pulmonar crônica e avaliar os resultados do tratamento, geralmente é muito mais importante que se compreenda os princípios segundo os quais o pulmão funciona do que concentrar-se apenas nos testes de função pulmonar.

Analisando a função pulmonar, a capacidade vital é o volume mais importante na avaliação do esforço do indivíduo e na presença de um componente restritivo da doença.

HUTCHINSON (1846) realizou um trabalho pioneiro sobre capacidade pulmonar e função respiratória com o objetivo de estabelecer um 
método para identificação de distúrbios pulmonares através do espirômetro. Vários termos hoje utilizados, como capacidade vital por exemplo, foram antecipados por ele.

Em indivíduos acima de 60 anos de idade o teste de função pulmonar pode ser utilizado para confirmar a presença de obstrução das vias aéreas. As medidas da capacidade vital e do volume residual são antigas e bem estabelecidas. Estes parâmetros são, respectivamente, o volume máximo de ar expirado depois de uma inspiração profunda e o volume que permanece nos pulmões.

As provas de função pulmonar auxiliam no diagnóstico das doenças pulmonares com a verificação de padrões ventilatórios (obstrutivos, restritivos ou mistos), controlam a evolução da doença e do tratamento, determinam testes de reversibilidade da obstrução das vias aéreas (prova broncodilatadora), ou de provocação brônquica, auxiliam nos estudos da fisiologia respiratória, epidemiológicos, farmacológicos e outros. As provas de função pulmonar também avaliam os riscos cirúrgicos e as mudanças da função pulmonar de acordo com a idade, sexo, etc. Para determinar se a redução da capacidade vital é decorrente da restrição ou obstrução, são obtidas as medidas dos valores do fluxo. Os valores do fluxo podem ser medidos diretamente ou determinados por observar o volume expiratório por um período de tempo.

Enquanto há uma variedade de testes de função pulmonar sofisticados, o mais informativo é o espirograma de expiração forçada. Atualmente é comum espirômetros eletrônicos fornecerem resultados como curvas de volume-tempo e fluxo-volume que mostram exatamente os mesmos dados em formatos diferentes.

Terminologicamente o termo espirometria é utilizado para os exames como instrumento de investigação clínica essencial que vem facilitando 0 
entendimento das respostas fisiológicas e patológicas ao exercício físico, como também a elaboração de programa terapêutico. Através desses testes determinam-se, identificam-se e avaliam-se, de maneira individualizada, adultos "sadios" com baixa capacidade funcional cardiorrespiratória, adultos sob risco de morte súbita relacionada à prática de exercícios físicos, adultos hipertensos que iniciarão prática desportiva.

As duas principais medidas objetivas da função pulmonar são espirometria e medições de pico de fluxo expiratório. A maioria dos estudos têm utilizado o volume expiratório forçado no primeiro segundo para documentar as alterações, mas com medidas de pico de fluxo expiratório os resultados obtidos sào similares.

\subsubsection{Espirometria}

A espirometria, do latim spirare que significa respirar e metrum que significa medida, é a medida do ar que entra e sai dos pulmões. É um teste que auxilia na prevenção das obstruções do fluxo aéreo e permite o diagnóstico e a quantificação dos distúrbios ventilatórios. Analisa a função ventilatória quantitativa e qualitativamente. Determina os volumes de ar exigidos em cada movimento respiratório. Cada volume depende da idade, sexo, condição de treinamento e do peso do corpo.

Espirometria deve ser feita na avaliação inicial e após tratamento para verificação de possível obstrução residual. Do ponto de vista da análise funcional, embora não forneça o diagnóstico médico, a espirometria permite conhecer com detalhes o grau e o tipo de distúrbio que envolve o sistema respiratório, mensurando com fidelidade a contribuição de todos os componentes do sistema (AZEREDO \& MACHADO, 1996). 
Os parâmetros indicativos de obstrução ao fluxo aéreo são obtidos da manobra de capacidade vital forçada na expiração. A manobra deve ser registrada graficamente e as curvas de volume-tempo e fluxo-volume devem, idealmente, acompanhar os valores numéricos. Isso permite a verificação da colaboração do indivíduo e da capacidade técnica do laboratório que realiza o teste. A curva de fluxo-volume permite avaliar melhor o esforço expiratório inicial ao demonstrar claramente o pico de fluxo que deve ser alcançado precocemente; já a curva volume-tempo demonstra melhor os critérios para aceitação do final da manobra e a duração da expiração, que deve ser, de no mínimo, 10 segundos em pacientes com obstrução ao fluxo aéreo. A gradação da gravidade da obstrução, uma vez detectada sua presença, baseia-se nos valores do $\mathrm{FEV}_{1}$ em relação aos previstos: valores $\leq 40 \%$, obstrução grave; entre 41 e $59 \%$, moderada; e $\geq 60 \%$, obstrução leve. Considera-se normal quando os valores forem $>80 \%$.

Em 1846, HUTCHINSON, em seu trabalho intitulado "On the capacity of the lungs and on respiratory functions", definiu e mediu a capacidade vital de quase 2000 indivíduos saudáveis e notou sua relação com o peso corporal, estatura e idade (PEREIRA, 1992). Quando os indivíduos não têm evidência de doença presente ou passada e as medidas são feitas de uma maneira-padrão, os dados obtidos são chamados de valores de referência. A maioria é baseada em valores retirados de amostras selecionadas.

Muitas tabelas foram obtidas antes do desenvolvimento de questionários respiratórios, padronizados e estabelecidos, de normas técnicas para cálculo das curvas e avaliação dos equipamentos de função pulmonar. 


\subsubsection{Espirometria simples ou convencional}

Essa técnica possibilita avaliar todos os volumes, capacidades e fluxos respiratórios diretamente, à exceção do VR, fornecendo ricas informações sobre a função pulmonar.

Por meio da espirometria simples é possível detectar valores considerados estáticos (volumes e capacidades) e valores considerados dinâmicos (fluxos). Nestes últimos, é possivel obter valores diretos e valores indiretos. E também por meio de testes pré e pós-broncodilatadores, obter informações sobre a natureza de uma anormalidade obstrutiva, isto é, se a anormalidade obstrutiva é de natureza orgânica (irreversivel) ou funcional (reversivel).

Para uma melhor compreensão da espirometria simples podemos classificá-la em estática e dinâmica. A espirometria estática não permite avaliar todas as condições da função pulmonar, mas fornece alguns volumes importantes como a CV. Os volumes pulmonares considerados fundamentais são medidos em libras ou em mililitros e compreendem: volume corrente (VC); volume de reserva inspiratória (VRI); volume de reserva expiratória (VRE) e volume residual (VR). É o volume de ar que permanece nos pulmões mesmo após uma expiração forçada e que só pode ser obtido por meio de equipamento com circuito fechado e com conhecimento prévio da quantidade e da porcentagem dos gases nele contidos. Não é possível obter este volume por meio da espirometria simples. Espirometria dinâmica envolve, além de volumes e capacidades, a velocidade com que o ar deixa os pulmões, isto é, o fluxo aéreo ou fluxo expiratório, que indica o tempo gasto para uma quantidade de ar passar pelas vias aéreas e chegar até a boca (COSTA, 1999). 


\subsubsection{Expiração forçada}

Um teste simples muito útil de função pulmonar é a medição de uma única expiração forçada. O volume exalado no primeiro segundo é chamado volume expiratório forçado (FEV) e o volume total exalado é a capacidade vital forçada (CVF). Normalmente o FEV é cerca de $80 \%$ da CVF. Uma medição correlata é a taxa de fluxo expiratório forçado (FEF) que é a taxa de fluxo médio, medida durante a metade do meio da expiração. Geralmente esta é estreitamente relacionada com o VEF, embora ocasionalmente esteja reduzida quando o FEV é normal. Ás vezes outros índices também são medidos a partir da curva de expiração forçada.

Uma maneira útil de examinar as expirações forçadas é com as curvas de fluxo-volume, obtidas registrando-se a taxa de fluxo em relação ao volume durante uma expiração forçada a partir da inspiração máxima, havendo uma redução à medida em que o volume pulmonar se aproxima do volume residual (VR).

Por meio dessas curvas podemos determinar o grau de obstrução das grandes e pequenas vias aéreas e os distúrbios ventilatórios restritivos.

As manobras espirométricas são realizadas em pé com as narinas fechadas por um clipe nasal, sendo obtidas pelo menos três curvas consistentes em expiração forçada de no mínimo 6 segundos cada.

A espirometria é realizada com um mínimo de três curvas consistentes (normas padronizadas pela ATP - American Thoracic Society 1995). A técnica mais prática para se medir valores de volume e de fluxo é com o espirômetro, o qual é utilizado para medir somente aqueles volumes que podem ser expelidos do pulmão. 
Neste estudo utilizou-se um espirômetro da marca Koko Spirometer (Pulmonary Data Service Instrumentation, Inc.), acoplado ao computador.

O equipamento informatizado para realizar as tarefas envolvidas nos testes de função pulmonar apresenta vantagens, tais como: menor número de erros de cálculo, calibrações realizadas mais consistentemente, redução na variabilidade de medidas repetidas, o tempo para obtenção final dos testes é reduzido para o avaliado e o técnico, procedimentos padronizados, armazenamento e recuperação de exames prévios para comparação de maneira rápida e eficiente. A repetição de testes esforço-dependentes ou com resultados questionáveis é prático porque a computação permite a inspeção imediata das medidas e impressão de relatórios e gráficos.

\subsubsection{Monitor de pico de fluxo expiratório (peak-flow)}

A mensuração do pico de fluxo expiratório (PEF), ou peak-flow, foi introduzida na Inglaterra no ano de 1959 por B. M. Wright, tendo por finalidade básica permitir avaliar com a máxima exatidão o grau da obstrução brônquica em diversas doenças pulmonares.

O primeiro aparelho médico a ser utilizado na mensuração do pico de fluxo expiratório máximo foi mérito de Wright que o idealizou e projetou e foi lançado no mesmo ano pela Airmed, recebendo a denominação de "Wright Peak Flow Meter."

Atualmente é o único aparelho portátil facilmente disponível e prático para uso nas medições. O peak-flow serve para medir o fluxo expiratório de uma maneira simplificada, rápida e segura. A vantagem constitui na detecção e avaliação precoce de uma obstrução brônquica e na sua reversibilidade. Mede o pico de fluxo expiratório máximo obtido durante uma expiração forçada 
iniciando com o pulmão inflado totalmente (capacidade pulmonar total - CT). Mostra uma medida reprodutível, quantitativa e simples e reflete, principalmente, a gravidade das obstruções nas grandes vias aéreas.

Pode ser totalmente normal quando o paciente apresenta obstrução acentuada das pequenas vias aéreas. Uma prova muito dependente de esforço do paciente. Bastante reprodutivel em pacientes que cooperam totalmente com o teste. É fácil de medir em domicílio e pode ser considerado normal quando o valor é acima de $75 \%$ do predito.

O valor a ser atingido para cada indivíduo é determinado através do sexo, idade e altura.

\subsubsection{Medidas do pico de fluxo expiratório (peak-flow)}

Como a medida do valor do fluxo expiratório é dependente do esforço, os indivíduos que serão avaliados precisam ser treinados inicialmente para obter um melhor resultado. O esforço requerido para realizar a medida é um sopro de ar máximo e curto, idêntico àquele requerido no esforço inicial para soprar uma bexiga. Deve-se instruir o individuo para:

1. Verificar se o marcador do aparelho está no ponto zero, colocando $o$ indicador na base da escala numerada;

2. Segurar o monitor de forma que o marcador fique livre, não obstruindo o orifício de saída do ar e o marcador;

3. Inspirar profundamente. Colocar o monitor na boca, fechar os lábios ao redor do bocal e expirar o mais forte e rápido possível;

4. Verificar a posição do marcador;

5. Repetir três vezes os passos 1,2 e 3 e anotar o resultado do maior valor obtido. 


\subsection{Coleta de dados}

A coleta de dados foi realizada em duas etapas:

$1^{\text {a }}$ etapa - Realizou-se uma avaliação pré-programa em cada indivíduo da amostra. Esta avaliação seguiu a seguinte ordem de testes:

a) Pico de fluxo expiratório (peak-flow);

b) Espirometria.

As mensurações foram realizadas por uma equipe de professores, técnicos e estudantes de educação física, no Laboratório de Fisiologia CENESP e nas dependências do Centro de Educação Física e Desportos da Universidade Estadual de Londrina, Paraná.

As medidas do pico de fluxo expiratório foram realizados semanalmente pela pesquisadora com auxílio dos estagiários acadêmicos de Educação Física da Universidade Estadual de Londrina-Pr, como atividade acadêmica complementar. As medidas foram tomadas sempre no início do programa. As medidas espirométricas foram realizadas pela técnica de espirometria do Centro de Práticas Esportivas da Universidade de São Paulo (CEPEUSP), sendo a mesma técnica a realizar as provas tanto na coleta de dados da pré quanto na pós-intervenção.

$2^{\text {a }}$ etapa - Após 12 semanas, realizou-se avaliação pós-programa, seguindo as ações da etapa anterior.

\subsection{Tratamento Estatístico}

Para a análise estatística das variáveis estudadas $\left(\mathrm{CVF}, \mathrm{FEV}_{\mathrm{l}}, \mathrm{PEF}\right.$ e $\mathrm{FEF}_{25 \%-75 \%}$ ) primeiramente os resultados foram descritos utilizando-se a estatística descritiva (média e desvio-padrão) e posteriormente as diferenças 
percentuais entre pré e pós-intervenção dos grupos experimental e comparativo foram contrastadas mediante o teste " $t$ " de Student, para amostras independentes, com número de elementos diferentes.

Para analisar a variável PEF das provas de pico de fluxo expiratório utilizou-se do teste de Análise de Variância para medidas repetidas (Anova one way), seguido do teste de Post Hock de Tuckey, uma vez que a prova de pico de fluxo expiratório foi realizada em todas as sessões do programa de atividade motora. O nível de significância adotado foi $\mathrm{p}<0,05$. Para o tratamento estatístico foi utilizado o software Statistica for Windows, versão 6.0.

\section{RESULTADOS E DISCUSSÕES}

Quando analisadas as variáveis da função pulmonar, os resultados encontrados apresentaram um aumento nos valores médios, tanto para o grupo comparativo quanto para o experimental, nas variáveis $\mathrm{PEF}$ e $\mathrm{FEF}_{25 \%-75 \% \text {. }}$ Comparando-se os resultados iniciais e finais das provas observou-se que, a variável PEF apresentou uma média de $16,4 \% \pm 16,3 \%$ para o grupo experimental e de $4,0 \% \pm 16,3 \%$ para o grupo comparativo. Na variável $\mathrm{FEF}_{25 \% \text { - }}$ $75 \%$ o grupo experimental apresentou uma média de $7,1 \% \pm 9,2 \%$ e o grupo comparativo de $5,1 \% \pm 10,3 \%$.

Os resultados das variáveis $\mathrm{CVF}$ e $\mathrm{FEV}_{1}$ apresentaram declínio após o período do programa de atividades motoras. O grupo experimental obteve uma média de $-6,9 \% \pm 6,5 \%$ e no grupo comparativo verificou-se uma média de $8,2 \% \pm 8,1$, conforme pode ser observado na FIGURA 1 . 


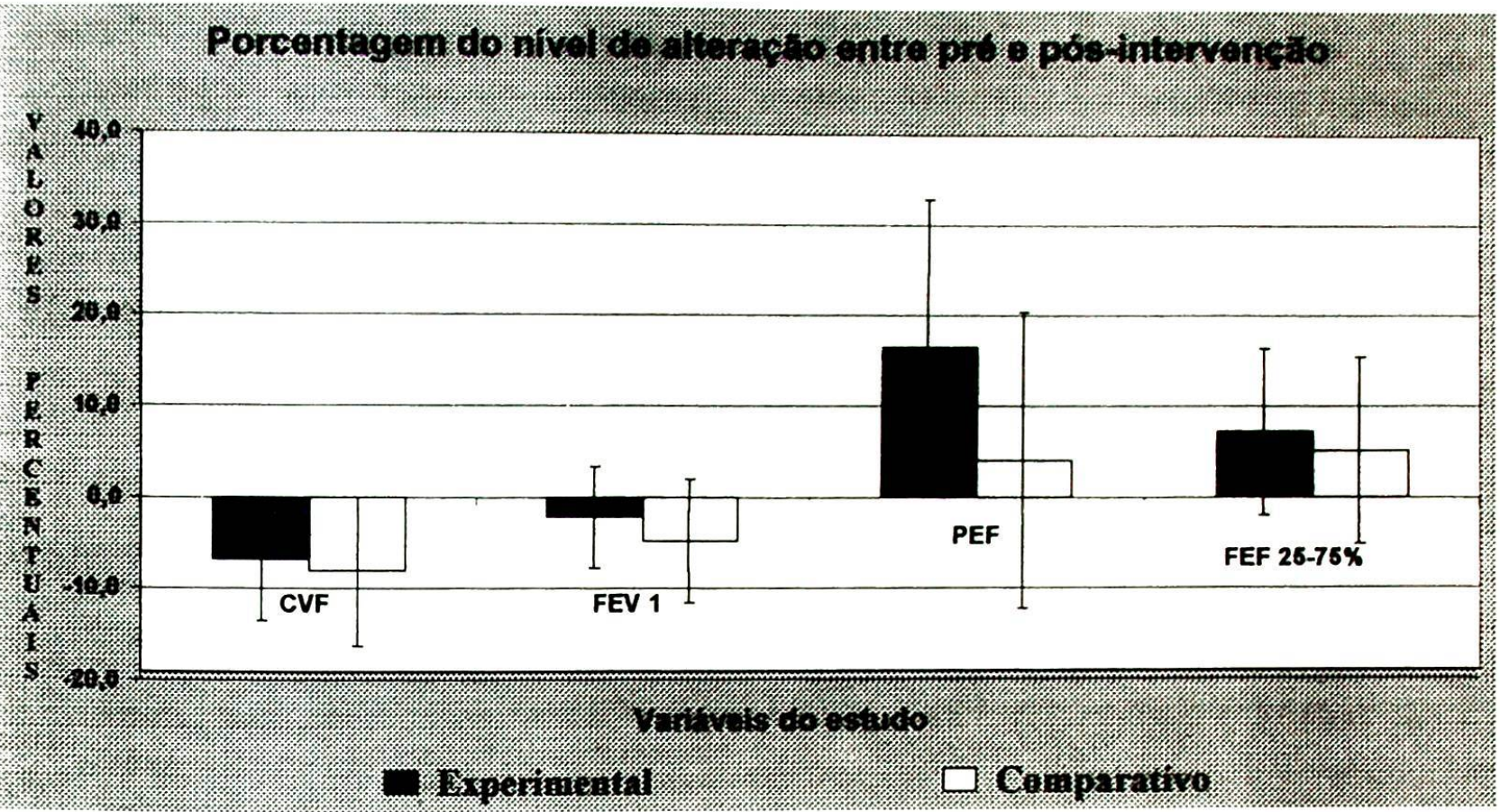

FIGURA 1 - Nível de alteração entre pré e pós-intervenção nas variáveis do estudo dos grupos experimental e comparativo (expressos em porcentagem)

No entanto, quando comparadas as médias do nível de alteração entre pré e pós-intervenção das variáveis $\mathrm{CVF}, \mathrm{FEV}_{1}, \mathrm{PEF}, \mathrm{FEF}{ }_{25-75 \%}$, o teste "t" de Student somente apresentou diferenças significativas para a variável PEF, conforme pode ser observado na TABELA 1.

TABELA 1 - Média e desvio padrão, valor do teste "t" de Student e valor do "p" para as variáveis $\mathrm{CVF}, \mathrm{FEV}_{1}, \mathrm{PEF}$ e $\mathrm{FEF}_{25-75 \%}$ dos grupos experimental e comparativo.

\begin{tabular}{rrrrrr}
\hline \multicolumn{2}{c}{ Grupo } & \multicolumn{2}{c}{ Grupo } & & \\
$\begin{array}{c}\text { Experimental } \\
\text { média }\end{array}$ & $\begin{array}{c}\text { Comparativo } \\
\text { desvio } \\
\text { padrão }\end{array}$ & média & $\begin{array}{c}\text { desvio } \\
\text { padrão }\end{array}$ & valor t & valor p \\
\hline$-6,9$ & 6,5 & $-8,2$ & 8,1 & 0,5 & 0,6 \\
$-2,2$ & 5,5 & $-4,8$ & 6,8 & 1,2 & 0,2 \\
16,4 & 16,3 & 4,0 & 16,3 & 2,1 & $0,0^{*}$ \\
7,1 & 9,2 & 5,1 & 10,3 & 0,6 & 0,6 \\
\hline
\end{tabular}

* diferença significativa - $p<0,05$ 
É possível que os mecanismos de resposta das vias aéreas para as variáveis $\mathrm{CVF}, \mathrm{FEV}_{1}$ e $\mathrm{FEF}$ 25-75\% tenham sido prejudicados por vários fatores, podendo ser pelo uso de medicações. Não foi solicitado a interrup̧̧ão das orientações médicas quanto à utilização de medicamentos nesse período. Um outro aspecto a ser lembrado é quanto às condições climáticas, pois a coleta de dados préintervenção foi realizada no período de inverno. Nessa estação o indivíduo apresenta maior probabilidade de alterações nas funções pulmonares, o que leva o indivíduo a fazer uso mais freqüente de medicações. A coleta de pósintervenção foi realizada no verão com uma condição climática mais favorável, periodo em que diminuem as obstruções e consequentemente o uso de medicações. Isto pode ter sido uma das causas das diferenças nos resultados entre o pré e o pós.

\section{ANDERSON (1993) e a AMERICAN THORACIC SOCIETY}

(1995) comentam que é de conhecimento público que, para uma certa temperatura e umidade, altos níveis de ventilação-minuto produzem um grau maior de obstrução de vias aéreas. Por outro lado, fixada uma determinada ventilação minuto, se o ar inspirado for quente e úmido, o grau de obstrução das vias aéreas é menor do que se inspirasse ar frio e seco. As condições corporais e ambientais de temperatura, pressão e umidade influenciam os valores dos volumes e fluxos medidos nas provas de função pulmonar (AMERICAN THORACIC SOCIETY, 1962).

Se a temperatura (em torno de $21^{\circ}$ na coleta inicial e $25^{\circ}$ na coleta do pós), pressão ambiental de $895 \mathrm{mmHG}$ e a umidade do ar fossem mais próximas, provavelmente as respostas obtidas nas variáveis que apresentaram diminuição não ocorreriam.

Vale ressaltar que devido às circunstâncias em que a coleta de dados se realizou, (diferença da umidade de ar do laboratório), pode ter havido 
interferências e tais resultados devem ser interpretados com bastante cuidado devido a essas ocorrências. Os resultados mostram quadros de alterações que são explicados no I Consenso Brasileiro sobre Espirometria (1996) em que até 5\% de erros sistemáticos na aferição do pneumotacógrafo é aceitável e podem ocorrer quando as condições ambientais forem diferentes.

As condições ambientais de temperatura foram diferentes nos períodos das coletas de dados, o que provavelmente causou uma diminuição em duas variáveis investigadas tanto no grupo experimental quanto no grupo comparativo. No entanto, esses resultados foram de magnitudes diferentes entre os grupos estudados, ou seja, tanto a melhora quanto a piora das variáveis durante o período do programa ocorreram em diferentes porcentagens de alterações.

Convém salientar que segundo NADEAU \& PERONNET (1985), não havendo nenhum tipo de patologia, a resistência das vias aéreas pouco muda com a idade, o que nos leva a crer, que mesmo em se detectando alguma alteração de ordem patológica, a atividade motora dentro de um plano de aplicação pode trazer vários benefícios para o praticante idoso, não só aos aspectos orgânicos, como também em outros aspectos que se refletem na qualidade e predisposição para uma vida ativa.

Um outro aspecto que merece atenção é quanto à participação ativa dos sujeitos no momento das provas, uma vez que, com base nas interpretações das curvas de esforço, $15 \%$ dos indivíduos não colaboraram totalmente com as manobras espirométricas, conforme encontrado no relato das fichas individuais, não apresentando esforço e cooperação durante o sopro, não realizando um sopro forte ou interrompendo antes do final da prova. A porção esforço-dependente da curva pode ser aumentada com maior esforço por parte do indivíduo. Assim, a 
falta de cooperação é um fator limitante para os testes e os resultados podem ser comprometidos.

Do grupo estudado, conforme relato e anexado no resultado das provas, $18 \%$ dos indivíduos apresentaram alterações no quadro de saúde, sendo que na coleta dos dados da pós-intervenção $6 \%$ estavam retornando de cirurgia e $12 \%$ com quadro gripal, resfriado, rinite alérgica ou sinusite. Esta informação sugere que o grau de comprometimento desses indivíduos era maior do que o diagnosticado inicialmente, mudando, desta forma, os resultados das provas. Estes resultados significam uma mudança no comportamento do indivíduo, podendo alterar a função pulmonar, visto que as crises são limitantes, impossibilitando a realização adequada das provas.

Outro fato que vale menção, quando se analisa os comprometimentos e intercorrências, refere-se às insuficiências respiratórias que foram diagnosticadas na pré-intervenção. Dentre todos os idosos avaliados no grupo experimental, 30\% apresentaram anormalidades na função pulmonar, com quadro de alterações nas variáveis estudadas. Os resultados da espirometria indicaram que $15 \%$ dos idosos apresentaram quadro de obstrução das vias aéreas, $9 \%$ apresentaram quadro de restrição e $6 \%$ com quadro misto (obstrução/restrição), conforme FIGURA 2. 
Distribuição dos participantes de acordo com as alterações ventilatórias

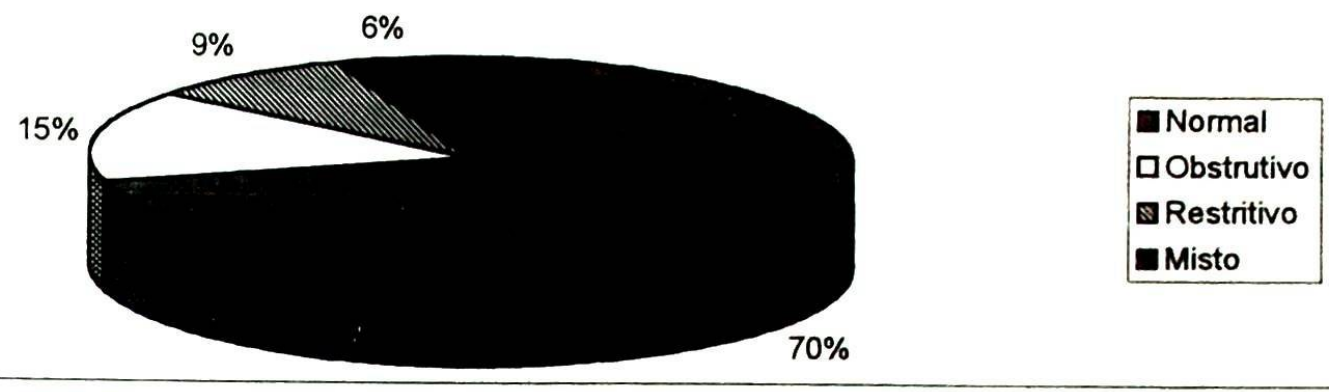

FIGURA 2 - Distribuição dos participantes de acordo com as alterações ventilatórias encontradas nas provas de pico de fluxo expiratório na pré-intervenção.

Ainda podemos considerar que por uma limitação de material para a avaliação inicial das provas, foram utilizados somente três bocais sendo que a umidade instalada nos filtros desses bocais pode também ter sido outro fator que interferiu nos resultados das provas de espirometria.

Descritivamente, os resultados apresentam médias diferentes entre os grupos, sendo que o GE apresenta sempre médias superiores ao GC. Quando contrastados os resultados entre os testes, nota-se que a maior variação foi registrada nas variáveis $\mathrm{CVF}$ e $\mathrm{FEV}_{1}$, provavelmente, decorrente principalmente por condição de doenças ou efeitos de remédios e/ou falta do indivíduo em manter o esforço ao realizar as manobras espirométricas.

Levando em consideração que estas variáveis dependem do esforço máximo com um sopro forte e contínuo, e tendo os indivíduos feito e treinado por 12 semanas nos testes de peak flow, que necessita de um sopro forte e curto, a tendência é realizar o sopro no espirômetro semelhante ao peak flow, ou seja, um sopro curto interrompendo antes de terminar a curva de esforço. Desta forma, geralmente não se conseguia fazer com que a CVF chegasse até o final da curva. No pré, como o indivíduo fez primeiro o teste de espirometria e depois as provas de peak flow, o esforço foi melhor manobrado do que no pós, que recebeu a 
interferência do treino de 12 semanas do peak flow. Isto pode ter sido a interferência para que os resultados do PEF e FEF $25 \%-75 \%$ tenham sido maiores do que as outras variáveis.

O ideal seria realizar primeiro os testes da espirometria e depois o pico de fluxo expiratório, por serem as manobras realizadas diferentemente.

\subsection{Análise da medida do pico de fluxo expiratório}

Durante todas as sessões do programa de atividade motora (12 sessões) houve avaliação do pico de fluxo expiratório somente para o GE. O grupo comparativo só compareceu no momento da coleta de dados da espirometria, da pré e pós-intervenção, não realizando os testes de peak-flow. Os resultados médios do grupo experimental estão expressos no FIGURA 3.

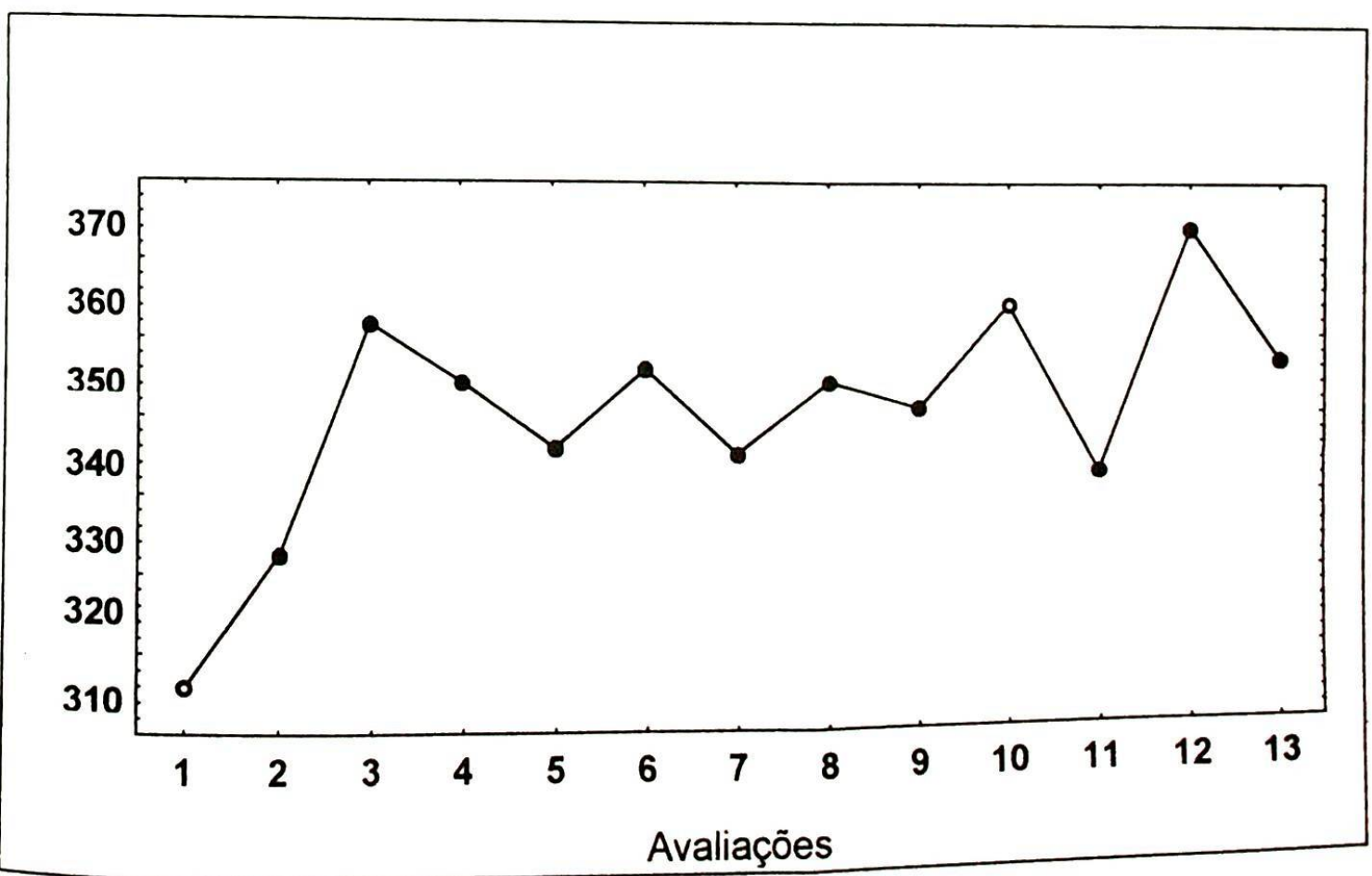

FIGURA 3 - Valores médios (média) do pico de fluxo expiratório em cada um dos momentos (12 avaliações mais a avaliação do pós-intervenção) do grupo experimental. 
Quando analisados os valores médios do pico de fluxo expiratório, o teste de variância para medidas repetidas (Anova One Way) mostrou haver diferença significativa $(F[12,132]=2,9985, \mathrm{p}=0,001)$, sendo que o teste de Tuckey localizou diferenças significativas somente da primeira para a terceira semana de intervenção do programa. Após a terceira semana ocorreu somente pequenas oscilações não significativas. No entanto, da $11^{\mathrm{a}}$ avaliação para a $12^{\mathrm{a}}$ avaliação é possível observar descritivamente um aumento nos valores médios do pico de fluxo expiratório.

É possível inferir com isso que o programa de atividades motoras teve efeito significativo nesta variável estudada, uma vez que os indivíduos eram sedentários e possibilitou uma melhora no momento em que os efeitos da prática ocorreu no organismo inativo. A melhora significativa na terceira avaliação pode ser entendida devido ao fato da amostra apresentar inicialmente baixos níveis de condicionamento fisico.

Segundo WILMORE \& COSTILL (1999), quanto maior for o nível inicial de condicionamento físico menor será a melhora relativa determinada pelo programa de treinamento.

Um outro aspecto a ser considerado é a possibilidade do efeito aprendizagem que ocorre na reaplicação de testes, pela adaptação e aperfeiçoado ao manuseio do monitor do pico de fluxo expiratório.

A medida do pico de fluxo expiratório isoladamente tem sido aceita como uma medida independente da função pulmonar. É recomendado que o valor do pico de fluxo expiratório seja utilizado como um parâmetro objetivo na avaliação dos sintomas e para as recomendações terapêuticas, quando tais recomendações dependem da gravidade da obstrução do fluxo respiratório. Mas o pico de fluxo expiratório não é suficiente para fazer um diagnóstico ou avaliar totalmente o comprometimento fisiológico do idoso. 


\section{CONCLUSÃO}

Os resultados deste estudo possibilitaram verificar as condições dos idosos do PIASI em relação à função pulmonar. As provas de espirometria e pico de fluxo expiratório forneceram importantes dados sobre o comportamento da mecânica respiratória dos idosos investigados. A espirometria é um exame simples apenas na aparência, encerrando muitos detalhes que influenciam sua análise e interpretação. A obtenção de testes adequados, entretanto, depende não só do equipamento utilizado, mas de compreensão e entusiasmo de quem realiza os exames, bem como da colaboração dos indivíduos testados.

Após análise de todas as variáveis investigadas, chegou-se às seguintes conclusões:

1. As variáveis PEF e FEF $25-75 \%$ apresentaram descritivamente valores de médias maiores na pós-intervenção do que o diagnosticado inicialmente. Entretanto, somente a variável PEF apresentou diferenças significativas entre os grupos em função de ser o parâmetro mais sensível para diagnosticar processos de obstruções das vias aéreas;

2. O tempo de 12 semanas do programa de atividades motoras parece não ter sido suficiente para promover mudanças significativas sobre as variáveis CVF e $\mathrm{FEV}_{1}$ ou por estas variáveis serem dependentes da cooperação dos indivíduos, sendo essencial a participação ativa para se obter resultados em condições ótimas;

3. O programa de atividades motoras melhorou significativamente o percentual da variável PEF após 12 semanas de intervenção;

4. Os resultados das provas de espirometria podem ser influenciados por fatores como condições climáticas, condições fisicas dos indivíduos investigados, tipos de patologias, estado psicológico dos indivíduos, temperatura 
ambiente, pressão atmosférica, que devem ser levados em consideração quando forem realizar novos testes;

5. Os dados do presente trabalho mostram que os estudos da função pulmonar e as avaliações espirométricas em idosos são recursos importantes para verificar variações e alterações ventilatórias;

6. Não foi possível comparar os resultados apresentados com outros estudos relacionados ao tema, pois não foram encontrados trabalhos mais recentes que abordassem a análise de variáveis da função pulmonar em idosos, submetidos a programas regulares de atividades motoras, assim como suas intercorrências;

7. São necessárias novas investigações com maiores períodos de intervenção dos programas de atividades motoras, maiores cuidados com as intercorrências, procurando diminuir as limitações. 


\section{REFERÊNCIAS BIBLIOGRÁFICAS}

ABBAS, A.K.; LICHYMAN, A.H.; POBER, J.S. Cellular and molecular immunology. Toronto, Saunders, 1995.

ADAIR, N. Chronic airflow obstruction and respiratory failure. In: HAZZARD, W.R.; BIERMAN, E.L.; BASS, J.P.; ETTINGER, W.H.; HALTER, J.B. eds. Principles of geriatrics and gerontology. 3 ed. New Yorks, Mc Graw-Hill, 1994. p.583-95.

AMERICAN THORACIC SOCIETY. Chronic bronchitis, asthma and pulmonary emphysema. American Review of Repiratory Disease, v. 85, p.762-8, 1962.

AMERICAN THORACIC SOCIETY/ MEDICAL SECTION OF THE AMERICAN LUNG ASSOCIATION. Standardization of Spirometry. Uptade, 1994. American Journal Respiratory Cit. Care Medicine, v. 152, p.1107-36, 1995.

ANDERSON, S.D. Exercise: induced asthma. In: MIDDLETON, E.; REED, C. E.; ELLIS, E.F., eds. Allergy: principles and practice. 4.ed. St. Louis, CV Mosby, 1993. p.1343.

ANDERSON, T.W.; BROWN, J.R.; HALL, J.W.; SHEPHARD, R.J. The limitations of linear regressions for the prediction of vital capacity and forced expiratory volume. Respiration, v.25, p. 465-84, 1968.

ANDREOTTI, L; BUSSOTTI, A.; CAMMELli, D.; AIELlO, E; SAMPOGNARO, S. Connective tissue in aging lung. Gerontology, v.29, p. $377-87,1983$.

ANTONIAZZI, R.M.C.A. A condição física do idoso. Santa Maria, 1994. 125p. Monografia (Curso de Especialização) - Universidade de Santa Maria. 
ASTRAND, I. Aerobic word capacity in men and women with special reference to age. Acta physiologica scandinava, v.49, p.11-226, 1960. Suplemento 169.

AZEREDO, C.A.C.; MACHADO, M.G.R. Fisioterapia respiratória moderna.

2. ed. São Paulo, Manole, 1996.

BABCOCK, M.A.; PATERSON, D.H.; CUNNINGHAM, D.A. and DICKINSON, J.R. Exercise on-transient gas exchange kinetics are slowed as a function of age. Medicine and Science in Sports and Exercise. v.26, p. $440-46,1994$.

BEAUVOIR, S. A velhice. 2 ed. Rio de Janeiro, Nova Fronteira,1990.

BERQUÓ, E. Algumas considerações demográficas sobre o envelhecimento da população no Brasil. In: SEMINÁRIO INTERNACIONAL SOBRE O ENVELHECIMENTO POPULACIONAL: UMA AGENDA PARA O FIM DO SÉCULO, Brasília, 1996.

BOEZEN, H.M.; RIJCKEN, B.; SCHOUTEN, J.P.; POSTMA, D.S. Falta de respiração em indivíduos idosos está relacionada à função pulmonar e reversibilidade da obstrução das vias aéreas. DIÁRIO RESPIRATÓRIO EUROPEU, v.12, N.4, p.805-10, Universidade Groningen, 1998 [ resumo registro Lilás $133 \mathrm{MN}]$.

BOTH, A. Fundamentos da gerontologia. Passo Fundo, Editora UPF, 1994.

BRASIL. Ministério da Justiça. Secretaria Nacional dos Direitos Humanos.

Política Nacional do Idoso: Programa Nacional de Direitos Humanos. Brasília, 1998.

BRINER JUNIOR.W.W.; SIIEFFER, A.L. Introduction: Exercise and Allergy. Official Journal of the American College of Sports Medicine, v.24, n.8, p.843-4, 1992. 
BURROWS, B.; LEBOWITZ, M.D.; CAMILLI, A .E.; KNUDSON, R.J. Longitudinal changes in forced expiratory volume in one second in adults. American Review of Respiratory Diseases, v.133, p. 974-80, 1986. CRAPO, R.O. The aging lung. In: MAHLER, D.A., ed., Pulmonary disease in the elderly. New York, Marcel Dekker, 1993. p.1-25.

COSTA, D. Fisioterapia respiratória básica. São Paulo, Atheneu, 1999.

COTES, J.E. Lung function. 5 ed. Oxford, Blackwell Scientific, 1993.

DAVIDSON, W.R.; FEE, E.C. Influence of aging on pulmonary hemodynamics in a population free of coronary artery disease. American Journal of cardiology, v.65, p. 1454-58, 1990.

DAVIES, B.H. The respiratory system. In: PATHY, M.S.J., ed. Principies and practice of geriatric medicine. 2 ed. Chichester, Wiley, 1991 . p. 663-81.

DEMPSEY, J.A ; POWERS, S.; GLEDHILL, N. Discussion: Cardiovascular and pulmonary adaptation to physical activity. In: BOUCHARD,C.; SHEPHARD, R.J.; STEPHENS, T.; SUTTON, J.; McPHERSON, B., eds. Exercise, fitness and health. Champaign, Human Kinetics, 1990. p.205-16. DEMPSEY, J.A .; SEALS, D.R.. Aging, exercise and cardiopulmonary function. In: LAMB, D.R.; GISOLFI, C.V.; NADEL E., eds. Perspectives in exercise science and sports medicine: Exercise in older adults, Indianapolis, Bench-mark Press, 1995. v.8, p. 237-97.

D'ERRICO, A .; SCARANI, P.; COLOSIMO, E.; SPINA, M.; GRIGONI, W. F.; MANCINI, A. M. Changes in the alveolar connective tissue of the ageing lung. Virchow's Archives: a Pathological Anatomy and Histopathology, v.415, p.137-44, 1989.

DILL, D.B.; HILLYARD, S.D.; MILLER, J. Vital capacity, exercise performance and blood gases at altitude as related to age. Journal of Applied Physiology. V.48, p.6-9, 1980. 
EDITORIAL, Jornal de Pneumologia, v.22, n.3, p.150-56, 1996.

ETNIER, J.; JOHNSTON, R.; DAGENBACH, D.; POLLARD, R.J.; REJESKI,W.J.; BAGA, M. As relações entre função pulmonar, aptidão aeróbia e desempenho cognitivo em idosos, pacientes de Doença Pulmonar Obstrutiva Crônica (DPOC).TÓRAX, v.116, n.4, p.953-60, Universidade Estadual de Arizona, E.U.A.,1999. [resumo registro Lilás, 246TB].

FARIA JUNIOR., A.; RIBEIRO, M.G.C. UNATI - Idosos em movimento: mantendo a autonomia. Evolução e referencial teórico. Rio de Janeiro, EdUERJ/UNATI, 1995.

GANNON, E.K. Correlação de força expiratória do músculo abdominal e funções pulmonares em idosos. Michigan, 1999. Tese (M.E.S.) Universidade de Oregon - Michigan do Norte. [resumo registro Discus 1975-2000/03 Desportivo].

GOBBI, S. Atividade fisica para pessoas idosas e recomendações da organização mundial de saúde de 1996. Revista Brasileira de Atividade Física e Saúde, v.2, n.2, p.41-9, 1997.

GOODWIN, T.S.; SEARLES, R.P.; TUNG, S.K. Immunological responses of a healthy population. Clinical and Experimental Immunology v.48, p.403$10,1982$.

HAYFLICK, L. H. Como e porque envelhecemos. Rio de Janeiro, Campus, 1996.

HORAN, R.F.; SHEFFER, A.L.; BRINER JUNIOR, W.W. Phisycal Allergies.

Official Journal of the American College of Sports Medicine, v.24, n.8, p.845-8, 1992.

HORVATH, S.M.; BORGIA, J.F. Cardiopulmonary gas transport and aging. American Review or Respiratory Diseases, v.129, p.568-71, 1984. 
HUTCHINSON, J. On the capacity of the lungs, and on the respiratory functions, with a view of establishing a precise and easy method of detecting disease by the spirometer. Medical Chirurgig Society , v.29, p. 137-45, 1846.

INSTITUTO BRASILEIRO DE GEOGRAFIA E ESTATÍSTICA. Estatísticas Históricas do Brasil. Rio de Janeiro, IBGE, 1987. v.3.

JOHNSON, B.D.; DEMPSEY, J. A. Demand vs capacity in the aging pulmonary system. Exercise and Sport Sciences Reviews, p.19, p.171210, 1991.

JOHNSON, B.D.; REDDAN, W.G.; PEGELOW, D.F.; SCOW, K.C.; DEMPSEY, J. A. Flow limitation and regulation of functional residual volume in a physically active aging population. American Review of Respiratory Diseases, v.143, p.960-67, 1991a.

JOHNSON, B.D.; REDDAN, W.G.; SCOW, K.C.; DEMPSEY, J. A.

Mechanical constraints on exercise hyperpnea in a fit aging population.

American Review of Respiratory Diseases, v.143, p.968-77, $1991 \mathrm{~b}$.

KOPILER, D.A. Atividade fisica na terceira idade. Revista Brasileira de Medicina e Esporte, v.3, n.4, p.108-12, 1997.

KURABAYASHI, H.; KUBOTA, K.; MACHIDA, I.; TAMURA, K.; TAKE, H.; SHIRAKURA, T. Effective physical therapy for chronic obstructive pulmonary disease. Pilot study of exercise in hot spring water. American Journal Physical Medicine Rehabillit, v.76, n.3, p. 204-7, 1997.

KWAN-GETT, TS.; LOZANO, P.; MULLIN, K.; MARCUSE, EK. One-year experience with an inpatient asthma clinical pathway. Arch Pediatric Adolescent Medicine, v.151, n.7, p.684-9, 1997.

LAKATOS, E.M.; MARCONI, M.A. Fundamentos da metodologia científica.

São Paulo, Atlas, 1991. 
LOHMAN, T.G.; ROCHE, A.F.; MARTORELL, R. Anthropometric standardization reference manual. Champaign, Human Kinetics, 1992. MATSUDO, S.M. Envelhecimento e atividade física. Atividades físicas para terceira idade. Brasília: SESI/DN,1997a.

MATSUDO, V.K.R., ed. Exercício aeróbico ou de força muscular melhora as variáveis da aptidão física relacionadas à saúde em mulheres idosas? Revista Brasileira de Atividade Física \& Saúde, v.2, n.3, p.36-49, 1997 b. MATSUDO, V.K.R.; MATSUDO, S.M. Prescrição e benefícios da atividade fisica na terceira idade. Revista Brasileira de Ciência e Movimento, v.5, n. 4, p. $42-6,1992$.

McARDLE, W.D.; KATCH, F.I.; KACTH, V.L. Fisiologia do exercício: energia, nutrição e performance humana. 3 ed. Rio de Janeiro, Guanabara Koogan, 1992. p.450-75.

MURRAY, J.F. In: SMITH, L.H.; THIERS, S.O., eds. Pathophysiology: the biological principles of discase. London, Saunders, 1981.

NADEAU, M.; PERONNET, F. Fisiologia aplicada na atividade física. São Paulo, Manole, 1985.

NERI, A.L. Qualidade de vida e idade madura. Campinas, Papirus, 1993. Psicologia do envelhecimento. Campinas, Papirus, 1995.

OKUMA, S.S. O idoso e a atividade física: fundamentos e pesquisa. Campinas, Papirus, 1998.

PENNOCK, B.E. Pulmonary function testing: what is "normal"? Archives Internal of Medicine, v.143, p.2123-7, 1983.

PEREIRA, C.A.C. Valores de referência para a espirometria em amostra da população brasileira adulta. Revista da SBAI, v.15, n.2, p.29-32, 1992.

PESCATELLO, L.S.; DI PIETRO, L. Physical Activity in older adults: an overview of health benefits. Sports Medicine, v.15, n.6, p.353-64, 1993. 
POLGAR, G.; PROMADHAT, V. Pulmonary function testing in children: technics and standards. Philadelphia, Saunders, 1971.

PRÉFAUT, C.; ANSELME, F.; CAILLAUD, C.; MASSÉ-BIRON, J. Exerciseinduced hypoxemia in older athletes. Journal of Applied Physiology, v.76, p.120-26, 1994.

REISER, K.M.; HENNESY,S.M.; LAST, J.A . Analysis of age-associated changes in collagen coss-linking in the skin and lung in monkeys and rats. Biochemica et Biophysica Acta, v.926, p.339-48, 1987.

ROCHA, R.R.; MAZO, G.Z. Situação dos idosos do programa de assistência ao idoso do IPESC. Caderno Adulto, n.4, p.65-76, 2000.

RODE, A.; SHEPHARD, R.J. Lung volumes of igloolik inuit and volochankanGanasan. Arctic Medical Research, v.55, p.4-13, 1996.

ROGHMANN, K.J. Immune response of elderly patients to pneumococcus. Journals of Gerontology, v.42, p.265-70, 1987.

SCHOUERI JUNIOR, R.; RAMOS, L.R. ; PAPALÉO NETTO, M. Crescimento populacional: aspectos demográficos e sociais. In: CARVALHO FILHO, E. T.; PAPALÉO NETTO, M., eds. Geriatria : fundamentos, clínica, terapêutica. São Paulo, Atheneu, 1994. p.9-29.

SHARRAT, M.; BRAWLEY, L.R. Impacto fisiológico e psicológico de exercício moderado em idosos previamente sedentários. Departamento de Cinesiologia, Universidade de Waterloo, 1988. [resumo registro Discus 1975-2000/03 Desportivo 86800039].

SHEPHARD, R.J. Physiological basis of training in elderly. Science \& Sports, v.9, n.4, p.189-96, 1994.

Exercise physiology. Toronto. B.C.Decker, 1997. 
SHIMURA, S.; BOATMAN, E.S.; MARTIN, C.J. Effects of aging on the alveolar pores of Kohn and on the cytoplasmic components of alveolar type II cells in monkey lungs. Journal of Pathology, v.148, p. 1-11,1986.

SMITH, E.L.; GILLIGAM, C. Exercise, sport and physical activity for the elderly: principles and problems of programming. In: Mc PHERSON, B. Sport and aging. Champaign, Human Kinetics, 1984. p.91-105. (1984 Olympic Scientific Congress Proceedings, v.5).

SPIRDUSO, W.; ECKERT, H. eds. Physical activity and aging. Champaign, Human Kinetics, 1989.

TEIXEIRA, L.R. Efeitos da individualização da intensidade de um programa de treinamento contínuo em variáveis respiratórias e hemodinâmicas de adolescentes asmáticos graves. São Paulo, EEFUSP,1996.

Importância das atividades físicas na profilaxia e terapêutica da asma.

Pediatria Moderna, v. 29, n. 7, p. 1006-12,1993a.

coord. Educação física escolar adaptada: postura, asma, obesidade e diabetes na infância e adolescência. São Paulo, EEFUSP/EFP, 1993b. . coord. Manual de orientação e utilização do monitor de pico de fluxo expiratório (PFE). São Paulo, CEPEUSP/ SBAI, 1999.

TEIXEIRA, L.R.; CABRAL, A L. B.; FERNANDES, A. L. G. Asma controle e prevenção. São Paulo, CEPEUSP/SPPT, 1999.

TERAMOTO, S.; FUKUCHI, Y.; NAGASE, T.; MATSUSE, T.; ORIMO, H. A comparison of ventilatory components in young and elderly men during exercise. Journal of Gerontology, v.50A, p.B34-39, 1995.

THURLBECK, W.M. Morphology of the aging lung. In: CRYSTAL, R.G.; WEST, J.B., eds. The lung. New Yorks, Raven Press, 1991. p.1743-48. 
TOCKMAN, M.S. Aging of the respiratory system. In: HAZZARD, W.R.; BIERMAN, E.L.; BLASS, J.P.; ETTINGER, W.H.; HALTER, J.B. Principles of geriatric medicine and gerontology. New Yorks, Mc GrawHill, 1994. p. 555-64.

VERAS, R.P. País jovem com cabelos brancos: a saúde do idoso no Brasil. Rio de Janeiro, 1994.

WEINECK, J. Biologia do Esporte. São Paulo, Manole, 1991.

WILMORE, J.H.; COSTILL, D.L. Physiology of sport and exercise. Champaign, Human Kinetics, 1999. 


\section{ANEXO I - Ficha individual da história clínica}

\section{IDENTIFICAÇÃO}

\section{NOME:}

Endereço:

Residência: ( )própria ( )alugada ( )pensão ( )com os filhos ou parentes

Data de nascimento: Idade: Sexo:

Cidade: Estado:

Estado Civil:

Formação escolar: ( ) primeiro grau ( ) segundo grau ( ) terceiro grau

Profissão que exerce ou exerceu:

Já trabalhou em ambiente com poeira por um ano ou mais?

( )Não

( ) $\operatorname{Sim}$

Especifique

Nivel sócio-econômico (renda familiar):

( ) até 1 salário minimo

( ) mais de 1 a 2 salários minimos

( ) mais de 2 a 3 salários mínimos

( ) mais de 5 a 10 salários minimos

( ) mais de 10 salários mínimos

Pratica algum esporte atualmente?

( )com orientação ( )sem orientação

Fuma? ( )Não ( )Sim cigarros por dia

Habitualmente tosse ou pigarreia pela manhã? ( ) Não

( ) $\operatorname{Sim}$

Habitualmente elimina catarro? ( ) Não

( ) $\mathrm{Sim}$

$\mathrm{O}$ peito chia com freqüência? ( ) Não

( ) $\operatorname{Sim}$

Possui algum problema de saúde?

Toma medicamentos? Quais?

Sente falta de ar?

( ) não sente ( ) Sim ( )leve ( ) moderada ( ) acentuada ( ) muito acentuada 


\section{ANEXO I - Ficha individual da história clínica (cont.)}

Já teve alguma doença pulmonar? ( ) Não

( ) $\mathrm{Sim}$

Qual?

Já submeteu a alguma cirurgia no pulmão?

( ) Não

( ) $\operatorname{Sim}$

Já precisou respirar por aparelho alguma vez?

( ) Não

( ) $\operatorname{Sim}$

Sintomas que apresenta

( ) Tosse

( ) chiado no peito

( ) aperto no peito

( ) falta de ar

( ) canseira freqüente

( ) rinite alérgica

( ) taquicardia

( ) caimbras freqüentes

( ) inchaço nas pernas

( ) articulações doloridas

( ) dores na coluna

( ) incontinência urinária

( ) problemas na visão

( ) problemas na audição

( ) insônia

( ) depressão

( ) diabetes

( ) osteoporose 
ANEXO II - Ficha individual da avaliação pulmonar

Nome.

Data de nascimento.

Endereço.

Data das avaliações:

Dia:

Horário: 
ANEXO III - Dados do sexo, idade, altura, peso dos indivíduos dos grupos comparativo e experimental, resultados obtidos no pré e pósintervenção do programa de atividades motoras nas variáveis $\mathrm{CVF}_{2} \mathrm{FEV}_{1}$, PEF e $\mathrm{FEF}_{25-75 \%}$ e a porcentagem de alteração entre pré e pós para cada variável $(\Delta)$.

\begin{tabular}{|c|c|c|c|c|c|c|c|c|c|c|c|c|c|c|c|c|}
\hline \multicolumn{17}{|l|}{ Grupo } \\
\hline & \multirow[t]{2}{*}{ sexo } & \multirow[t]{2}{*}{$\begin{array}{l}\text { Idade } \\
\text { (anos) }\end{array}$} & \multirow[t]{2}{*}{$\begin{array}{c}\text { Altura } \\
\text { (metros) }\end{array}$} & \multirow[t]{2}{*}{$\begin{array}{l}\text { Peso } \\
(\mathrm{Kg})\end{array}$} & \multicolumn{4}{|c|}{ CVF } & \multicolumn{3}{|c|}{ FEV, } & \multicolumn{2}{|c|}{ PEF } & \multicolumn{3}{|c|}{ FEF 25-75\% } \\
\hline & & & & & Pre & Pos & $\Delta$ & pre & pos & $\Delta$ & pre & Pos & $\Delta$ & pre & pos & $\Delta$ \\
\hline & $\mathrm{F}$ & 64 & 169 & 62 & 14 & 9 & -5 & 9 & 9 & 0 & -2 & 13 & 15 & -23 & -15 & 8 \\
\hline & $F$ & 64 & 156 & 78 & 1 & 1 & 0 & 6 & 15 & 9 & 26 & 39 & 13 & 13 & 14 & 1 \\
\hline & $F$ & 64 & 160 & 80 & -9 & -10 & -1 & -5 & -6 & -1 & -15 & 9 & 24 & -15 & -19 & -4 \\
\hline & $F$ & 67 & 150 & 66 & -15 & -27 & -12 & -26 & -30 & -4 & -29 & -27 & 2 & -61 & -53 & 8 \\
\hline E & $F$ & 60 & 147 & 62 & -11 & -22 & -11 & -17 & -18 & -1 & 5 & 10 & 5 & -44 & -30 & 14 \\
\hline$x$ & $F$ & 80 & 164 & 64 & 3 & -3 & -6 & 8 & 8 & 0 & 29 & 34 & 5 & 5 & 24 & 19 \\
\hline $\mathbf{P}$ & $F$ & 71 & 144 & 38 & 16 & 10 & -6 & 31 & 26 & -5 & 37 & 50 & 13 & 64 & 64 & 0 \\
\hline$E$ & $M$ & 68 & 164 & 68 & -14 & -20 & -6 & -11 & $\cdot-11$ & 0 & 24 & 17 & -7 & -16 & -14 & 2 \\
\hline $\mathbf{R}$ & $F$ & 62 & 151 & 91 & 15 & 3 & -12 & 10 & 1 & -9 & -11 & -6 & 5 & -17 & -20 & -3 \\
\hline I & $F$ & 69 & 169 & 90 & -11 & -25 & -14 & -5 & -13 & -8 & 6 & 6 & 0 & 36 & 53 & 17 \\
\hline$M$ & $F$ & 63 & 151 & 73 & 26 & 19 & -7 & 21 & 27 & 6 & -25 & 19 & 44 & -14 & 21 & 35 \\
\hline$E$ & $F$ & 61 & 141 & 67 & 18 & 3 & -15 & 18 & 11 & -7 & 6 & -1 & -7 & -6 & 3 & 9 \\
\hline$N$ & $F$ & 69 & 156 & 74 & -2 & -13 & -11 & -17 & -16 & 1 & 0 & 8 & 8 & -54 & -40 & 14 \\
\hline $\mathbf{T}$ & $F$ & 62 & 152 & 84 & -12 & -22 & -10 & -8 & -15 & -7 & -47 & -4 & 43 & -20 & -14 & 6 \\
\hline A & $F$ & 65 & 146 & 62 & 19 & 11 & -8 & 22 & 14 & -8 & 5 & 12 & 7 & 13 & 12 & -1 \\
\hline \multirow[t]{6}{*}{ L } & $F$ & 73 & 162 & 107 & -55 & -43 & 12 & -53 & -44 & 9 & -76 & -25 & 51 & -62 & -53 & 9 \\
\hline & $F$ & 65 & 153 & 53 & -20 & -22 & -2 & -11 & -17 & -6 & -13 & 11 & 24 & 10 & 10 & 0 \\
\hline & $F$ & 63 & 147 & 67 & 1 & -18 & -19 & -2 & -13 & -11 & -13 & 16 & 29 & -18 & -8 & 10 \\
\hline & $\mathrm{F}$ & 61 & 166 & 71 & 9 & 6 & -3 & 14 & 12 & -2 & 16 & 42 & 26 & 7 & 8 & 1 \\
\hline & $\mathrm{F}$ & 62 & 149 & 66 & 13 & 8 & -5 & 21 & 20 & -1 & -3 & 24 & 27 & 29 & 35 & 6 \\
\hline & $\mathrm{F}$ & 70 & 165 & 91 & 16 & 12 & -4 & 17 & 16 & -1 & 2 & 20 & 18 & 0 & -1 & -1 \\
\hline
\end{tabular}


ANEXO III - Dados do sexo, idade, altura, peso dos indivíduos dos grupos comparativo e experimental, resultados obtidos no pré e pósintervenção do programa de atividades motoras nas variáveis $\underline{\mathrm{CVF}}, \mathrm{FEV}_{1}, \mathrm{PEF}$ e $\mathrm{FEF}_{25-75 \%}$ e a porcentagem de alteração entre pré e pós para cada variável $(\Delta)$ (cont.).

\begin{tabular}{|c|c|c|c|c|c|c|c|c|c|c|c|c|c|c|c|c|}
\hline \multicolumn{17}{|l|}{ Grupo } \\
\hline & \multirow[t]{3}{*}{ sexo } & \multirow{3}{*}{$\begin{array}{l}\text { Idade } \\
\text { (anos) }\end{array}$} & \multirow{3}{*}{$\begin{array}{c}\text { Altura } \\
\text { (metros) }\end{array}$} & \multirow{3}{*}{$\begin{array}{l}\text { Peso } \\
\text { (Kg) }\end{array}$} & \multirow{2}{*}{\multicolumn{4}{|c|}{ CVF }} & \multirow{2}{*}{\multicolumn{3}{|c|}{ FEV 1}} & \multirow{2}{*}{\multicolumn{2}{|c|}{ PEF }} & \multirow{2}{*}{\multicolumn{3}{|c|}{ FEF 25-75x }} \\
\hline & & & & & & & & & & & & & & & & \\
\hline & & & & & Pre & Pos & $\Delta$ & pre $F$ & pos & $\Delta F$ & pre $p$ & pos & $\Delta$ & pre & pos & $\Delta$ \\
\hline C & $\mathrm{F}$ & 71 & 149 & 61 & 32 & 12 & -20 & 30 & 16 & -14 & -5 & -6 & -1 & 6 & 7 & $\overline{1}$ \\
\hline 0 & $F$ & 63 & 160 & 61 & 13 & 20 & 7 & 23 & 28 & 5 & 16 & 46 & 30 & 45 & 26 & -19 \\
\hline$M$ & $F$ & 60 & 153 & 66 & -18 & -20 & -2 & 14 & 15 & 1 & -4 & -9 & -5 & -3 & 3 & 6 \\
\hline $\mathbf{P}$ & $\mathrm{F}$ & 80 & 158 & 55 & 15 & 8 & -7 & 13 & 11 & -2 & 2 & -6 & -8 & -11 & 4 & 15 \\
\hline A & $\mathrm{F}$ & 69 & 159 & 60 & -1 & -23 & -22 & 4 & -14 & -18 & 14 & 9 & -5 & 30 & 34 & 4 \\
\hline $\mathbf{R}$ & $M$ & 79 & 167 & 63 & -3 & -14 & -11 & 2 & -6 & -8 & 7 & 15 & 8 & 14 & 13 & -1 \\
\hline A & $F$ & 67 & 151 & 48 & -8 & -17 & -9 & -8 & -9 & -1 & 24 & 13 & -11 & -15 & 5 & 20 \\
\hline $\mathrm{T}$ & $M$ & 73 & 171 & 55 & -23 & -26 & -3 & -17 & -18 & -1 & 13 & 20 & 7 & -6 & 9 & 15 \\
\hline 1 & $F$ & 70 & 150 & 70 & -74 & -77 & -3 & -76 & -78 & -2 & -80 & -80 & 0 & -87 & -88 & -1 \\
\hline v & $\mathrm{F}$ & 76 & 151 & 64 & -27 & -30 & -3 & -20 & -20 & 0 & -25 & 14 & 39 & -27 & -14 & 13 \\
\hline \multirow[t]{2}{*}{0} & $F$ & 68 & 161 & 70 & -2 & -15 & -13 & 5 & -6 & -11 & 22 & 32 & 10 & 36 & 41 & 5 \\
\hline & $\mathrm{F}$ & 66 & 153 & 75 & -27 & -39 & -12 & -28 & -35 & -7 & -15 & -31 & -16 & -44 & -41 & 3 \\
\hline
\end{tabular}


APÊNDICE 1 - Aprovação do comitê de bioética do Hospital Universitário de Londrina - Paraná

\author{
1 II Universidade \\ Estadual de Londrina
}

HOSPITAL UNIVERSITÁRIO REGIONAL DO NORTE DO PARANÁ

COMITÉ DE BIOÉTICA

PARECER BIO 047/00

\author{
A SRA \\ LUCÍLIA KUNIOSHI UTIYAMA \\ Centro de Educação Física e Desporto \\ Universidade Estadual de Londrina \\ NEST A
}

Prezada Senhora,

O Comitè de Ética em Pesquisa analisou e aprovou o Projeto de Pesquisa "EFEITOS DE UM PROGRAMA DE ATIVIDADES MOTORAS NAS VARIAVÉIS DA FUNÇÃO PULMONAR DE IDOSOS', bem como O Termo de Consentimento Informado que está de acordo com a Resolução 196/96 -CONEP .
Londrina, 16 de agosto de 2000.

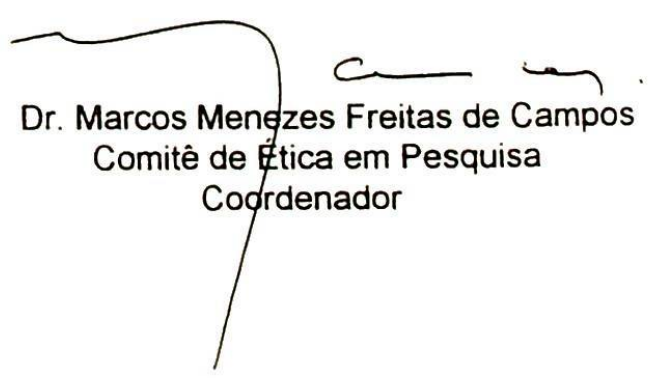




\section{APÊNDICE 2 - Termo de Consentimento}

Durante o periodo em que estiver vinculado ao Programa Interdisciplinar de Assistência a Saúde do Idoso pelo Hospital das Clínicas da Universidade Estadual de Londrina-Paraná (PIASI/HC/UEL), serão tiradas medidas do seu corpo como o seu peso e a sua altura com a finalidade de obter dados para as provas de função pulmonar. Serão feitas medidas da sua respiração que determinarão as condições da sua capacidade pulmonar no início e após programa de atividades motoras com sessões de exercicios, caminhada e hidroginástica. $\mathrm{O}$ objetivo deste estudo é avaliar a capacidade respiratória dos participantes do grupo.

Estas avaliações trarão beneficios no que se referem ao conhecimento do diagnóstico e orientações através dos resultados obtidos, não representando riscos ao voluntário.

Para isto, é necessário ter sua concordância com relação à utilização desses dados para estudo e divulgação de pesquisas. A sua identidade será mantida anônima e você poderá deixar de participar deste estudo no momento em que desejar.

Prof Lucilia Kunioshi Utiyama

Resp. pelo Programa da Ed.Física

CONCORDO:

Nome:

de 2000 